
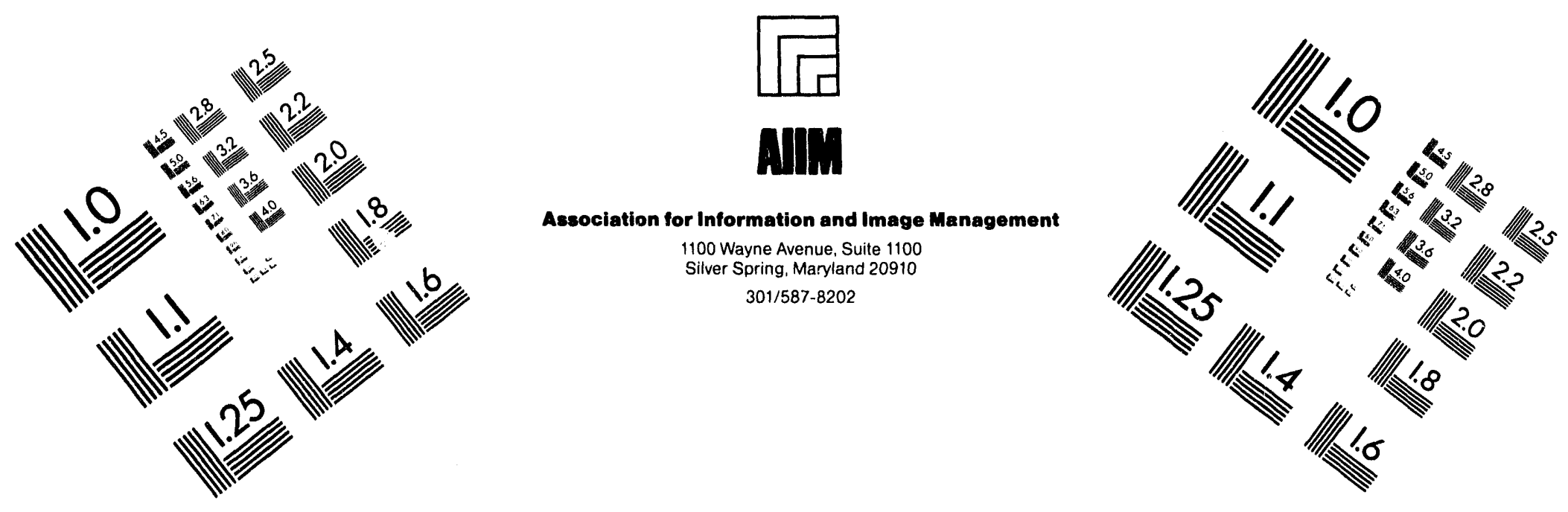

\title{
Centimeter
}

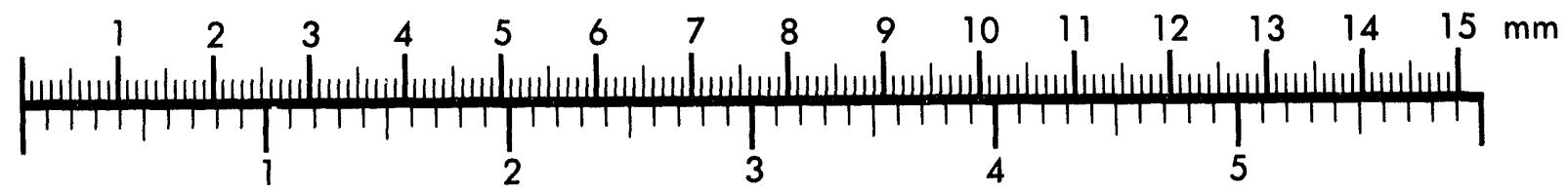
Inches
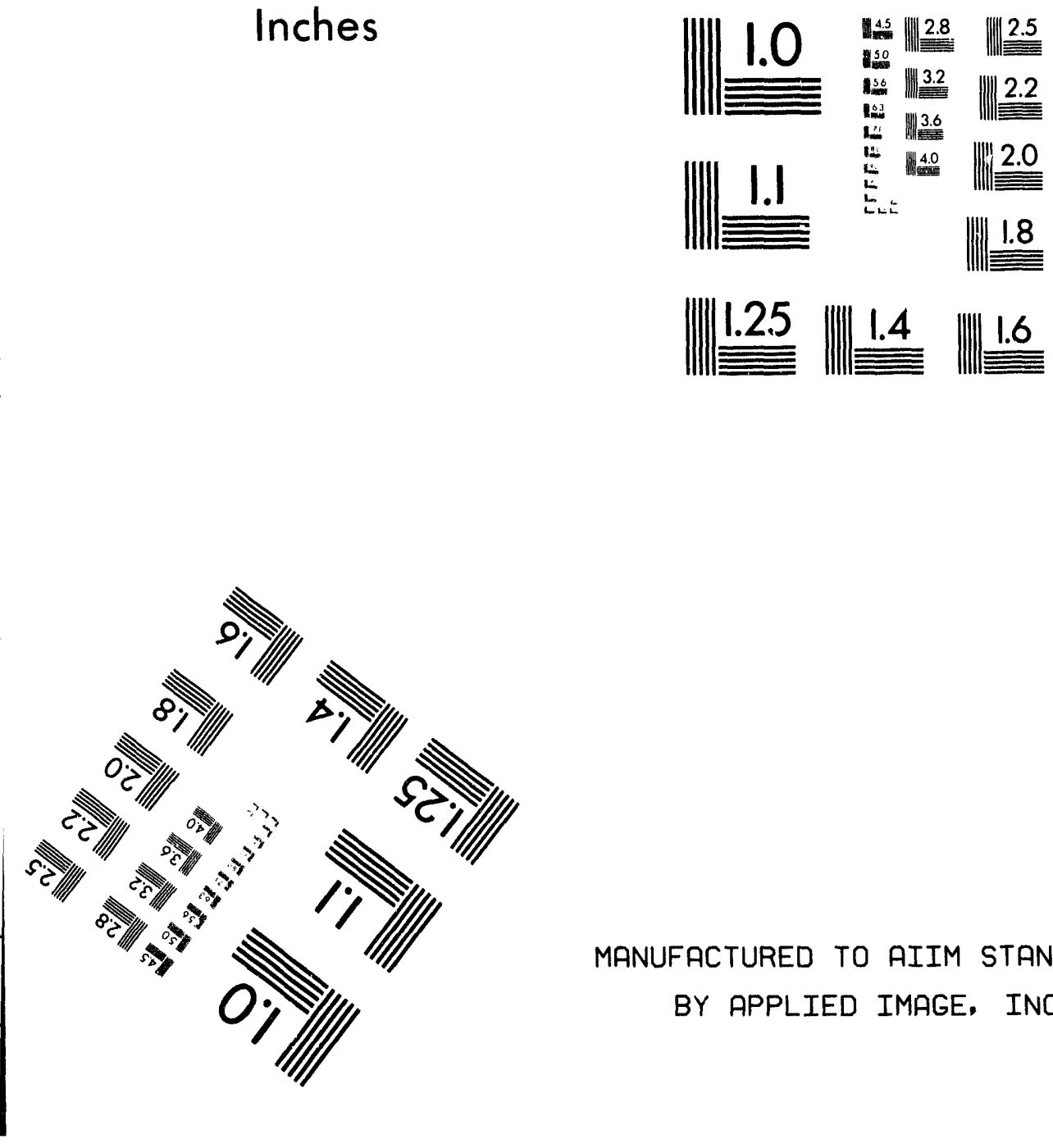

MANUFACTURED TO AIIM STANDARDS BY APPLIED IMAGE, INC.

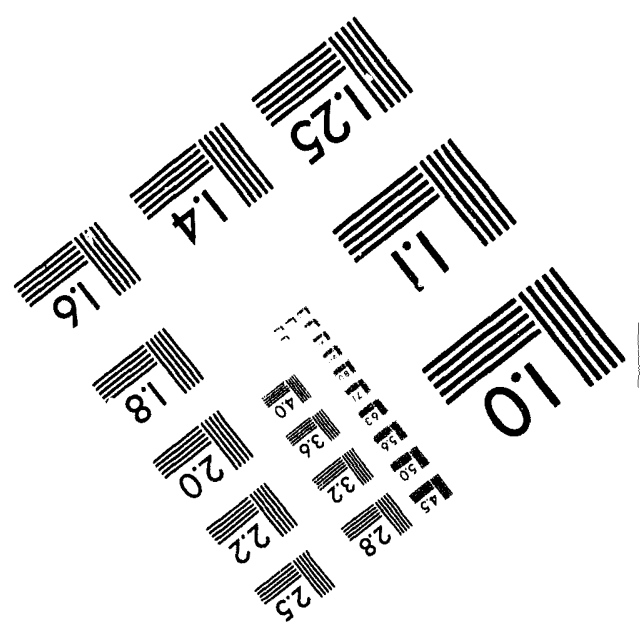



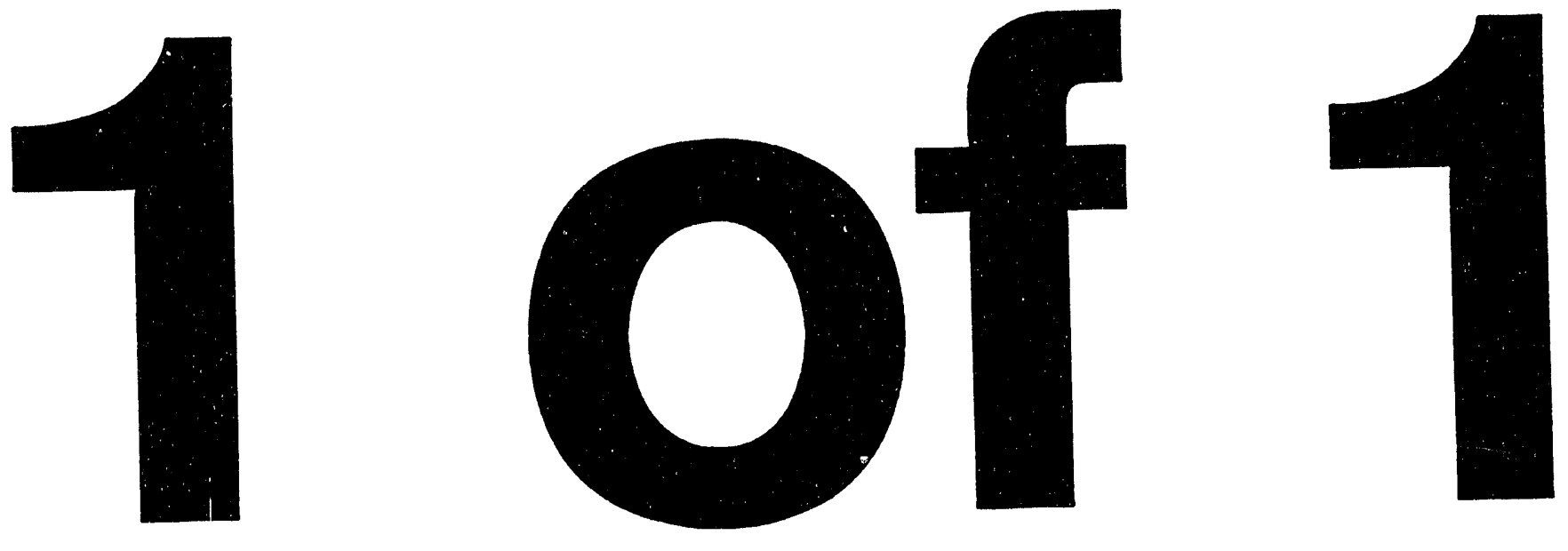


\section{dBASE IV Basics}

Catalog Tools Exit

IBASE IV CONTROL CENTER

CATALOG: C:IDBASEIUNTITLED.CAT

\begin{tabular}{|c|c|c|c|c|c|}
\hline Data & Queries & Forms & Reports & Labels & Applications \\
\hline :create> & <create> & <create> & :creates & screate & -create> \\
\hline & & & & & \\
\hline & & & & & \\
\hline & & & & & \\
\hline & & & & & \\
\hline & & & & & \\
\hline
\end{tabular}

File:

New file

Description: Press Enter on <create> to create new file

Help:F1 Use: \& Data:F2 Design: Shift-F2 Quick Report: Shift-F9 Menus: F10 


\section{dBASE IV Basics}

Catalog Tools Exit

dBASE IV CONTROL CENTER

CATALOG: C:IDBASEIUNTITLED.CAT

\begin{tabular}{|c|c|c|c|c|c|}
\hline Data & Queries & Forms & Reports & Labels & Applications \\
\hline <create> & <create> & <create> & <create> & screates & <create> \\
\hline & & & & & \\
\hline & & & & & \\
\hline & & & & & \\
\hline & & & & & \\
\hline & & & & & \\
\hline & & & & & \\
\hline
\end{tabular}

File: $\quad$ New file

Description: Press Enter on <create $>$ to create new file

Help:F1 Use: \& Data:F2 Design: Shift-F2 Quick Report: Shift-F9 Menus: F10

The Goverment reserves for itself and

others acting on its behalf a royalty free,

nonexclusive, irrevocable, world-wide

license for goverrmental purposes to publish,

distribute, translate, duplicate, exhibit,

and perform any such data copyrighted by

the contractor.

Prepared By: Pat O'Connor

Computing and Communications Division

(c) 1994 


\section{WHAT IS A DATABASE?}

A database is a set of information organized in a specific manner. Databases appear in every-day life...your telephone book, a file cabinet, your cook book...all can be considered databases that hold common information pertaining to a specific topic.

\section{About dBASE IV}

dBASE IV is a popular software application that can be used on your personal computer to help organize and maintain your database files. It is actually a set of tools with which you can create, organize, select and manipulate data in a simple yet effective manner. dBASE IV offers three methods of working with the product.

Control Center: This is dBASE IV's menu-driven interface that provides centralized access to all of dBASE IV's features and commands. The Control Center is most often used by students new to the product. However, you may find that the Control Center, when used to its fullest potential, offers all the power you may ever need in designing and maintaining your database files.

Command Line: The dBASE IV command line gives direct control of command input to the user. The dBASE IV command language features over 400 functions and commands that can be used to accomplish both simple and complex operations. When in Command Line mode, commands are entered at the "dot prompt" $(\bullet)$ displayed at the lower left corner of your screen. You should have a basic knowledge of the available commands and their exact structure (or syntax), before attempting to venture into the command line mode!

Programming: You can create your own custnmized, menu-driven applications by storing dBASE IV commands in a program. Using dBASE commands to automate systems requires a thorough background in the dBASE IV command language and an understanding of programming concepts. Therefore, dBASE IV programming is often utilized by more advanced users of the application. However, simple programs can be created by even novice users!

\section{System Requirements}

To use dBASE IV you need:

- An IBM or IBM-compatible 286, 386 or 486 computer

- $\quad 2 M B$ RAM

- 7.5 MB hard disk space to install all dBASE IV options -or- 4.5 MB hard disk space to install the basic dBASE IV system files only.

- DOS 3.3 or higher 


\section{DATABASE TERMS}

Frequently, a simple business rolodex file is used to present the concepts of a database... Each card in the rolodex file is equivalent to

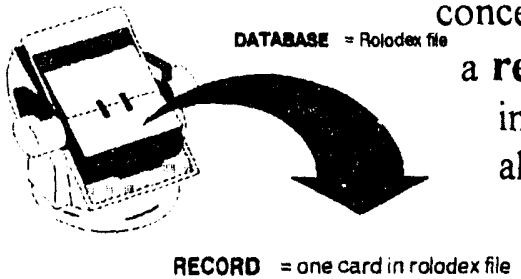

record in your database. Each card has several pieces of information, and each card has the same kind of information as all the other cards. There is one card, or one record

corresponding to each person represented in your rolodex file, or database.

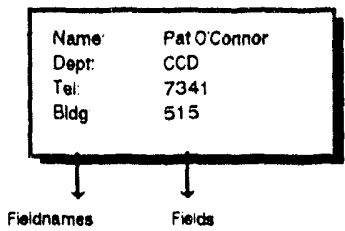

A field is a database category. It is used to store a particular type of data. Fieldnames define the field (or category) into which you are entering information. In the rolodex example used here, one of the fieldnames,

person in the current card or...record.

BLDG defines the field holding the actual building number of the

The entire collection of cards in your rolodex can be considered to be a database of information pertaining to the people you may frequently call as business contacts.

The information on each of your rolodex cards would be stored in a database file as a table of rows and columns:

\begin{tabular}{|c|c|c|c|c|}
\hline NAME & DEPT & TEL & BLDG & $\rightarrow$ These are the fieldnames \\
\hline Bunny, Bugs & Marketing & 1111 & 332 & \\
\hline Duck, Daffy & $P R$ & 7676 & 746 & \\
\hline Mouse, Mickey & Personnel & 3456 & 333 & $\rightarrow$ This is one record in the database! \\
\hline O'Connor, Pat & $\mathrm{CCD}$ & 7341 & 515 & \\
\hline
\end{tabular}

In this example, the fieldnames, NAME, DEPT, TEL and BLDG are arranged as your column headings defining each field. Each row is equivalent to one record containing the name, department, telephone and building number of each person in the database.

\section{Key Facts}

A Dbase IV file can contain up to 255 fields. A single record may contain up to 4,000 bytes. A single file may contain over one billion records and can be as large as two billion bytes. It is important to note, however, that the number of fields, records and size of your database is associated with your specific workstation and how much disk space is available for use. 


\section{Starting dBASE IV}

If you are on a stand-alone PC (i.e., not accessing $\mathrm{DBASE}$ from a network), and $\mathrm{ABASE}$ has been installed on your $\mathrm{C}$ : drive, follow these steps to initialize the dBASE IV program:

1. At the $\mathrm{C}: 1>$ prompt, change into the directory holding the dBASE program files by typing CD\DBASE and press Enter $\rightarrow$.

$\triangle$ Special Note: the directory holding your $d B A S E I V$ program files may have been called something other than DBASE. You may want to get a listing of the current directories that are present on your hard drive by typing $D I R *$ at the $C: 1>$ prompt.]

2. At the C: $: D B A S E>$ prompt, access the program by typing DBASE and press Enter

$\neg$ Special Note: If you are accessing $\mathrm{dBASE}$ from a network, see your network system administrator for directions on starting the program.

\section{HELP}

dBASE IV offers on-line help to assist you through the program. Press F1 to access help on the current command or menu choice.

1. Press $F 1$ to access the help screen.

2. A help screen related to the current operation will be displayed.

$\rightarrow$ Use the F3 and F4 function keys to navigate up and down the help screens.

- The CONTENTS option will display a Table of Contents of help topics.

- The RELATED TOPICS option displays other topics related to the current help item.

- The PRINT option will send the displayed Help screen to your printer.

- BACKLP displays the last Help screen viewed.

3. Press EsC to close the Help screen and return to the Control Center screen 


\section{THE CONTROL CENTER}

The dBASE IV Control Center is the navigational center of the dBASE IV menu system. It displays a simple interface from which you can:

- Create database files

- Use database files

- Display and edit specific information

- Design and print reports and labels

- Design and run customized applications

- Manage your files... and more!

$\triangle$ Special Note: If the Control Center is not automatically displayed when you access $\mathrm{ABASE}$, you must type the word Assist at the dot prompt (.) that appears at the lower left portion of your screen and press Enter $\varangle$.

\section{Parts of the Control Center Screen}

Menu Bar: Provides pull-down menus as useful tools for creating, editing and managing your files. The Control Center's menu bar is located at the upper left portion of the screen and contains three options: Catalog, Tools and Exit.

Catalog Name: Displays the name of the catalog currently in use. A catalog is a group of files that you want to handle together.

Panels: There are six possible design

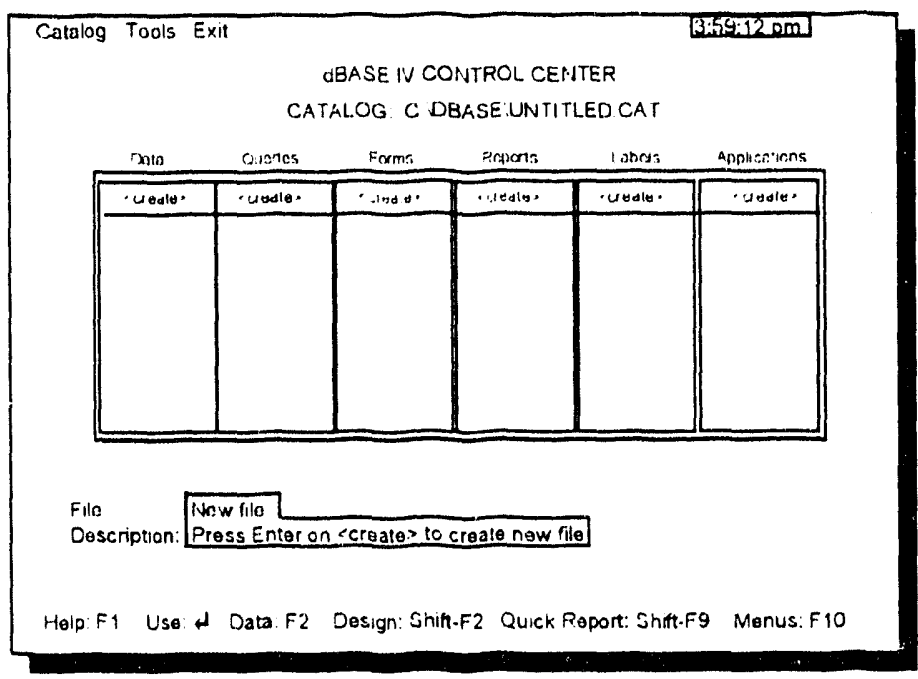
and display panels available in the Control Center... Data, Queries, Forms, Reports, Labels and Applications. The <create $>$ marker in each panel is used to create that type of file. Each panel can list up to 200 files.

Status Bar: Displays the File name and Description of the highlighted file.

Navigation Line: Located at the bottom of the Control Center screen, the Navigation Line displays a listing of "shortcut" keys... Help:F1, Data:F2, etc.

Message Line: dBASE IV will prompt you with helpful messages during certain operations. The message line overlays the navigation line when it is displayed. 


\section{Choosing Menu Options}

The Menu Bar that appears at the top of the Control Center is merely the top level of a number of menus that are nested within the dBASE IV program. However, the methodology for accessing any menu bar that may appear is consistent throughout the application.

To select a menu option, use the following steps:

1. Activate the menu by press the F10 function key.

2. Use the left and right arrow keys to move to the command key word. The pull down menu associated with the highlighted option will appear beneath it.

3. Use the up and down arrow keys to highlight the specific command from the appropriated pull down menu and press Enter $\square$.

- or-

Hold down the Alt key and press the first letter of the pull down menu you need to access. For example, to display the Exit pull down menu, hold down the Alt key while you press the letter E.

\section{Navigating through the Control Center's Panels}

When the Control Center is first displayed, the highlight appears on the <create $>$ marker of the Data panel. Use the following keys to move the highlight within the panels:

- $\Theta$ or $\Theta$ moves the highlight between panels

- $\uparrow$ or $\downarrow$ highlights the <create> marker or individual filenames within a panel

- Home and End moves the highlight between the top and bottom of a panel

- Page U and PageDown moves the cursor up and down a long list of filenames, one page at a time.

\section{Catalogs}

A catalog is a file you can create to group related files that you may use for a particular purpose so that they can be quickly and conveniently accessed when needed. Many people view catalogs as performing a similar function to that of creating DOS directories. Yes, they are both used to organize files but in different ways:

DOS directories can be thought of as drawers in a filing cabinet. Each file is in a particular directory (or file c'rawer) and, if you delete a file from a directory, it is permanently remo' ed from your disk.

Catalogs, on the other hand, organize your files by simply making a "list" of them. A catalog file does not contain the actual files but, information pertaining to each of the files contained within it... filename, file type, alias name (if any), path and description. Removing a filename 


\section{Catalogs, cont'd}

from one catalog removes the filename from your catalog "list" but, it doesn't affect other catalogs and it doesn't physically remove the file from your disk. A cat extension is automatically added to any catalog file you create. dBASE IV uses a default catalog named, Untitled.cat if you do not create a catalog of your own. Because this catalog file contains no files information, the Control Center will, initially, display no filenames in any of its panels.

Once you begin working with ABASE IV and create various catalog files, you can use the following steps to access a different catalog or create a new one:

1. Press Alt $+C$ from the Control Center's Menu Bar to display the Catalog option.

2. Highlight Use a diffcrent catalog and press Enter - .

3. Highlight the catalog you want to use or select the <create $>$ option to create a new one.

The catalog you selected will be the current catalog.

To add a file to a catalog:

1. Press Alt $+C$ from the Control Center's Menu Bar to display the Catalog option.

2. Highlight Add file to catalog and press Enter 4 .

3. Select the file you would like to add to the catalog.

4. Enter a brief summary of the database file and press Enter $\square$.

The file you have added will appear in the appropriate panel of the Control Center.

\section{Setting the Default Directory}

Before beginning your dBASE IV session, you should designate a default directory to which you would like all of your data saved to and retrieved from. Initially, dBASE will use the directory where its program files are stored as your default directory. It is wise to establish a different drive and/or directory to hold all the data files ycu create using dBASE.

To change the default directory:

1. Press Alt $+T$ to activate the Tools option in the Control Center's Menu Bar.

2. Highlight the DOS Utilities option and press Enter -

The DOS Utilities screen will appear.

3. Press Alt $+D$ to activate the DOS utilities screen's Menu Bar and use your arrow key to highlight its $D O S$ option.

4. Highlight Set default drive:directory option and press Enter $\square$

5.. Enter the drive: Ipath that you would like to use and press Enter - .

6. Press Alt $+E$ to display the Exit menu and press Enter - to return to the Control Center. 


\section{CREATING A DATABASE}

\section{THE DATABASE STRUCTURE}

When creating a database, it is important to think about its structure...exactly what information it will hold and how it will hold it. Creating a database structure is similar to designing a form into which information will be entered. You must define field names, field types and field widths to accept your data. Think about what the purpose of your database is. Will it be used to organize the names and addresses of clients? Perhaps it will be used to track the inventory in your company. Or, maybe you'll be using it to simply record the batting averages of your child's Little League team! Whatever the intended use of the database may be, ask yourself the following questions before you proceed to create your database:

1. What names will you assign to the fields?

2. What type of information will be entered into each field (character, numeric, etc.)

3. How wide must each field be?

\section{Field Names}

- Field names cannot be longer than ten characters long

- Each field name must begin with a letter

- Field names cannot contain blank spaces

- Field names may contain any letter, number or the underscore $\left(_{-}\right)$character

\section{Field Types}

Character: Stores any character that you can enter from the keyboard. These characters include any letters, numbers, special symbols or spaces that would not otherwise be used for calculations.

Numeric: Numbers that are used for calculations. The numeric field type can store integers and decimal numbers.

Float: $\quad$ Stores floating point numbers which are usually used in scientific applications.

Date: $\quad$ Date information. dBASE IV stores dates in MM/DD/YY format by default.

Logical: $\quad$ Stores either true or false value. Logical fields actually display "flags" indicating if a condition is true or false. $\mathrm{Y}=\mathrm{Yes}, \mathrm{N}=\mathrm{No}$; or $\mathrm{T}=\mathrm{True}, \mathrm{F}=\mathrm{F}$ alse are the only entries made into logical fields.

Memo: Memo fields are most often used to store large amounts of textual information. The text is not stored in the field itself, but in a file which is an auxi.'iary file to the database file. Read more about memo fields later in these notes. 


\section{Field Width}

\section{Field Type}

Character

Numeric

Float

Date

Logical

Memo

\section{Maximum Width}

254 characters

20 (the decimal point and any sign is included in field width, if present)

20 (the decimal point and any sign is included in field width, if present)

8 (this width is fixed and cannot be changed)

1 (this width is fixed and cannot be changed)

Displays as 10 , however, this field can contain up to 5,000 characters. The memo field is simply used as a "pointer" indicating where the text is stored.

\section{CREATING A DATABASE}

1. If your cursor is not already positioned there, move to the Data panel of the Control Center screen and highlight its $<$ create $>$ marker. Press Enter - . The following Database Design screen will appear:

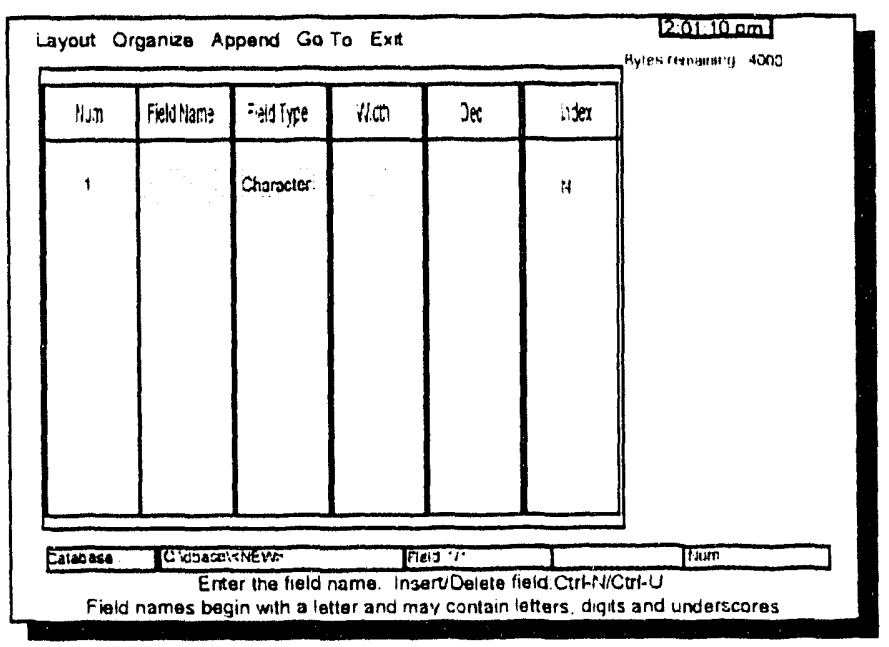

2. Type the first field name and press Enter - Your cursor will automatically jump to the Field Type column.

3. Choose the field type by entering the first character of the desired field type: Character, Numeric, Float, Date, Logical or Memo. OR, press Spacebar to cycle through the available field types. Press Enter $\square$. The cursor moves to the Field Width column

4. Enter the required field width and press Enter $\rightarrow$. Special Note: You'll notice that you will not have to enter widths for date, logical or memo fields since these are predefined by the system.

5. If you have chosen a Numeric type field, the cursor will jump to the Dec (decimal) column. Enter the appropriate number of decimal places, if any, you would like represented in that ficld. Press Enter $\square$

6. Press Spacebar to designate a Yes or No on the Index column. When index is set to Yes for a field, dBASE IV creates an index "tag" based on the value of the field described in that row $\rightarrow$ Special Note: You cannot index Logical or Memo fields. Read more about ordering your database with indexes in PART IV, ORGANIZING YOUR DATA.

7. Repeat steps 2 through 6 for each field name you would like to create 


\section{Creating a Database, cont'd}

8. Press Alt + E to display the Exit option in the Menu Bar. Highlight Save changes and exit and press Enter -

9. You will be prompted to enter a filename for your database. Type the file name of your choice and press Enter $\leftarrow$.

$D$ Special Note: $A B A S E$ IV filenames follow the same naming conventions as are applied in all DOS applications (up to eight characters in length, no spaces in the filename, any combination of letters and/or numbers.) dBASE IV automatically adds a dbf extension to any database file you create.

10. You will be returned to the Control Center screen. Note that the name of the newly created database appears in the Control Center's Data panel!

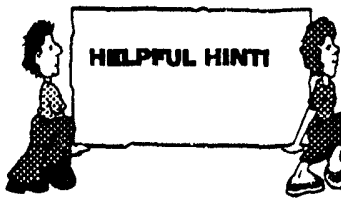

You can use the following cursor movement guidelines to assist you in navigating through the Database Design screen:

\begin{tabular}{|l|l|}
\hline Key... & Action... \\
\hline Enter - or Tab & Move to next column \\
\hline Shift + Tab & Move to previous column \\
\hline Tor $\square$ & Move up and down rows \\
\hline$\oplus$ or $\rightarrow$ & Moves left or right within a column \\
\hline
\end{tabular}




\section{MODIFYING THE DATABASE STRUCTURE}

While you may have planned the structure of your database very carefully, you will often find that necessary changes might have to be made subsequent to its creation. For example, you may want to add a new field to the database, delete one that's not being used, change the name of a field or its width. You can make any of these changes to your existing database's structure without losing any data you may have previously entered.

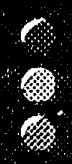

CAUTION! Never, never, never modify the structure of an existing database without first making a backup copy of the database just in case! You can use the DOS Copy command to make a duplicate copy of your dbf file to another disk. If you're unfamiliar with using the DOS Copy command, see the section on Dos Utilities.

To modify the structure of an existing database:

1. At the Control Center screen, highlight the database file in the Data panel that you need to change and press Enter - .

2. An overlay box will be displayed. Highlight its Modify structure/order option and press Enter - .

3. The Organize menu will be automatically displayed. Press ESC to remove it from your screen.

4. The structure of your database as you previously created it, will be displayed. You can now proceed to make the necessary changes to your database's structure...

\section{To add a field to the database structure:}

- Move the cursor to the first new blank field using your down arrow key (or press Pageoown)

- Enter all pertinent information for the new field (name, type, width, etc.)

- Press Ctrl E when you are finished.

- dBASE IV will display a prompt asking if you want to save your changes. Press Y for Yes

\section{To insert a new field into the database structure:}

- Position your cursor on the current field you would like to insert the new field above.

- Press $\mathrm{Ctr}+\mathrm{N}$. A new blank field will be inserted.

- Enter all pertinent information for the new field and press Ctrl + End when you are finished

- dBASE IV will display a prompt asking if you want to save your changes. Press Y for Yes

To delete a field from the database structure:

- Position your cursor on the field you would like to delete

- Press Ctrl U. The field will be deleted.

- Press Ctrl End when you are finished.

- dBASE IV will display a prompt asking if you want to save your changes. Press Y for Yes 


\section{Modifying the Database Structure, cont'd}

To edit information within previously created fields:

- Make any necessary changes to a field's name, type or width.

- CAUTION...do not change the field width and the field name or type at the same time! dBASE IV makes a temporary backup file of the data and copies any existing data back into this file. If both the field name and the width or type are changed, dBASE is may be unable to correctly copy all the data back into the file. Therefore, make one change, save the structure and then make the next change. 
Once you have established the structure of your database, it can be $u$ sed to add, edit, display or delete records.

\section{Selecting a File}

1. At the Control Center screen, highlight the database file in the Data panel and press Enter

2. An overlay box will be displayed. Highlight its Use file option and press Enter - .

3. The file is now open and ready for use. You will note that the file's name is now displayed above the horizontai line in the Data panel.

\section{ENTERING AND ADDING RECORDS IN THE DATABASE}

\section{To enter records to a newly created database:}

1. At the Control Center screen, highlight the database file in the Data panel into which you would like to enter/add records.

2. Press F2. This is the Data function key.

3. The dBASE IV Edit screen will appear. Enter the data for each field, pressing Enter $\square$ each time you would like to move to the next field. DSpecial Note: If you enter the maximum number of characters in a field, the computer will beep (known in dBASE; as the "bell") and your cursor will automatically jump to the next field. When you have entered the information in the final field of a record, the cursor will automatically jump to the first field of a new record.

4. When you have finished entering your data, press Cirl End to save your newly entered records and return to the Control Center screen.

\section{To add records to an existing database...}

1. At the Control Center screen, highlight the database file in the Data panel into which you would like to enter/add records.

2. Press the Data function key, F2

3. Press Alt $+\mathrm{B}$ to access Records menu.

4. Select $A d d$ new records and follow steps $\# 3$ and $\# 4$ as noted previously for entering records in a newly created database. 


\section{Entering and Adding Records to the Database, cont'd}

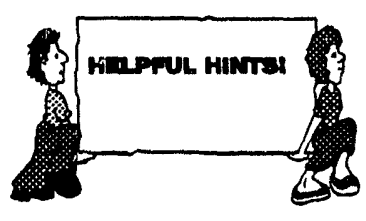

- The Status Line at the bottom of your screen will display the current database's path and filename. In addition, the Status Line will also display the record number you are positioned at. Read more about the Record Pointer in Part III, Using a Database.

- You can press the EsC key to stop the data entry operation (instead of Ctrl] + End) and return to the Control Center screen. BUT... keep in mind that the current record you are entering information to will not be saved!

\section{Entering Data In Memo Fields}

If you have added a memo-type field to your database's structure, you will find that memo field data entry is unlike any other field-type in dBASE IV. Each memo field can contain up to 64,000 characters. Text can be entered into Memo fields via the same data entry screen as used for other field types (follow the directions for entering and adding data as noted on the previous page.) However, to actually place the required information in your memo fields, you must:

1. Position the cursor on the memo field.

2. Press Cirl +Home. dBASE IV will display its own word processing screen for memo field entry.

3. Enter the required text.

4. Press Ctrl + End to save your memo information and return to the Edit screen.

5. Press Ctrl End again to exit the Edit screen and return to the Control Center

DSpecial Note: You will notice that the word memo will be displayed in lower case when your memo field is empty and converted to uppercase (MEMO) when it contains information. 


\section{DISPLAYING AND EDITING RECORDS}

Want to take a look at the records you have entered in a database? You can look at them one record at a time while in the Edit screen or, you can display multiple records, one screen at a time, while in the Browse screen.

1. If your database is already selected, skip to step \#2. Otherwise, at the Control Center screen, highlight the database file in the Data panel into which you would like to enter/add records.

2. Press the Data function key, F2. The Edit screen will appear. Press F2 to toggle to the Browse screen.

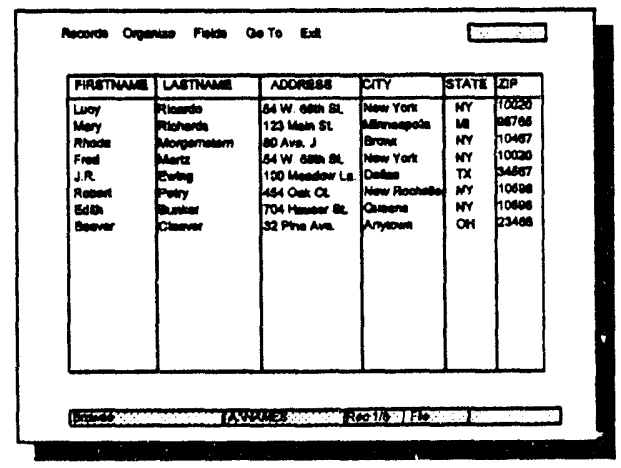

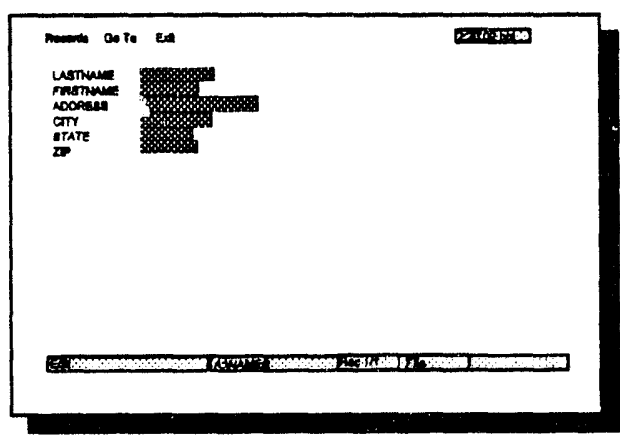

Sample Edit Screen

3. Press $F 2$ to continue to toggle back and forth between the Edit and Browse screens as required.

4. Press Ctrl End when you want to return to the Control Center screen.

Sample Browse Screen

Navigating Through Edit and Browse Screens

\begin{tabular}{|c|c|c|}
\hline Key, & Eulut Screen.. & Hrowse Screen.. \\
\hline$\Phi$ & Previous field & Previous record \\
\hline 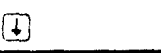 & Next field & Next record \\
\hline 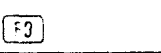 & Previous field & Previous field \\
\hline F & Next field & Next field \\
\hline Pagevo & Previous record & Previous screen \\
\hline Propeown & Next record & Next screen \\
\hline GiII + Page UD & First record & First record \\
\hline 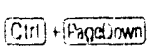 & Last record & L.ast record \\
\hline ao & Next field & Next lield \\
\hline $\sin +\overline{1 a 0}$ & Previous field & Previous licld \\
\hline isma & Beginning of ficld & Beginning of record \\
\hline Eniij & lind of licld & lind of record \\
\hline
\end{tabular}




\section{Editing Data}

You can edit data while in either the Edit or Browse screens. Keep these helpful keystrokes in mind when changing existing database information:

\begin{tabular}{|l|l|}
\hline Keystroke.. & Action.. \\
\hline Insert & $\begin{array}{l}\text { Toggles between insert and typeover mode. When in insert mode, characters } \\
\text { will be inserted to the left of the cursor position in your field. When in } \\
\text { typeover mode, characters will be replaced at the cursor position. }\end{array}$ \\
\hline Delete & Deletes the character at the cursor position \\
\hline$\leftarrow$ Bksp & Removes the character(s) to the left of the cursor. \\
\hline Cirn $+Y$ & Deletes all data from the current field \\
\hline
\end{tabular}

$D$ Special Note: Press Ctrt] End to save the changes you have made and return to the Control Center-or-press EsG to return to the Control Center without saving your changes!

\section{Special Browse Commands... The Fields Menu}

Use the Fields menu while in the Browse screen to help you display your data more effectively.

\section{- Lock Fields on Left}

dBASE IV displays eact record in your database across a row while in the Browse screen. Often, if you have a large number of fields in your database, they will not be visible on the screen at one time. The Lock Fields on Left option is invaluable when you would like to select a number of fields (or just one field) to remain stationary on your screen while scrolling to the right to view other fields that may not be currently visible.

1. While at the Browse screen, position your cursor in the field you would like to lock and press Alt $+F$ to access the Field menu.

2. Choose the Lock field on left option.

3. Enter the appropriate number of fields to the left of the current cursor position to be locked and press Enter - . 


\section{Special Browse Commands... The Fields Menu, cont'd}

\section{- Blank Field}

This Field menu command will delete the data from the current field

1. While in the Browse screen, move to the field in your database from which you would like to delete data.

2. Press Alt $+F$ to access the Field menu.

3. Choose the Blank field option.

- Freeze Field

Freeze a field so that it will become the only field that can be edited. IBASE IV will not allow your cursor to move to any other column in the database. This is a helpful speedup tip when entering data!

1. While in the Browse screen, press $\overline{A l t}+F$ to access the Fields menu.

2. Choose the Freeze field option

3. Enter the name of the field you would like to freeze

DSpecial Note: To "unfreeze" a field, select the Freeze field option again, delete the frozen field's name and press Enter

\section{- Size Field}

You can change the display width of your data with the Size field command. IMPORTANT: This will not change the width of the field in the actual database, only the width of the field while it is displayed in the Browse screen. (See Modifying the Database Structure later in these notes for information about changing the actual size of a field.)

1. While in the Browse screen, move to the field whose width is to be changed.

2. Press $A$ Alt $+F$ to access the Fields menu.

3. Select the Size field option.

4. Use your left and/or right arrow keys to adjust the width of the field and press Enter $\square$ when your finished 


\section{The Record Pointer}

Only one record can be added or edited at a time. Many dBASE commands affect only the current record therefore, understanding the concept of the record pointer is very important.

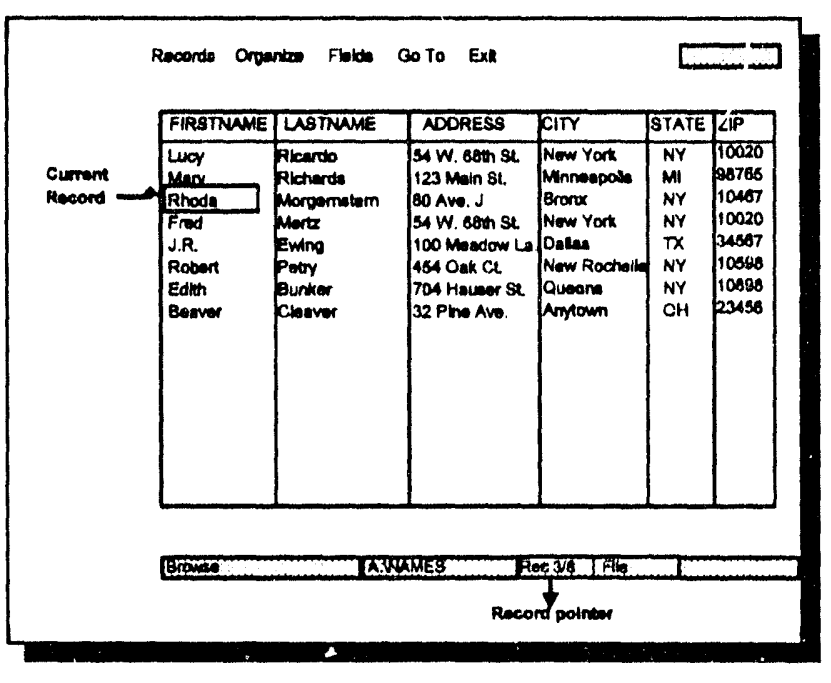

In the illustration to the left, the Browse screen is displayed and the cursor is highlighting the third record in the database. It is, therefore, the current record. You can quickly determine exactly which record number is current by noting its reference on the third section of the Status Bar at the bottom of the screen. For example, Rec: $3 / 8$ would mean that the Record Pointer is on number 3 of 8 records.

$\checkmark$ Special Note: EOF displayed in the Status Bar as the current record indicates that your pointer is at the end of the current database file and a new record can be added, if necessary

\section{Deleting and Recalling Records}

Deleting records from a dBASE IV database is a two-step process. Records must be marked before being deleted. Why? To protect you, that's why! Records marked for deletion are not permanently removed from your file until you specifically issue the command to delete them just in case you've accidentally marked the wrong record or, change your mind about just what is to be deleted.

\section{STEP I: To mark specific records for deletion}

1. While in the Browse or Edit screen of the appropriate database, highlight the record you are planning to delete.

2. Press Alt $+B$ to access your Browse or Edit screen's Records menu.

3. Highlight the Mark record for deletion option and press Enter $\rightarrow$. The record is now marked for deletion. Note the Del indicator in your Status Bar at the bottom of your screen. $\rightarrow$ Special Note: The option on the Records memu will automatically move to the ("lear. deletion mark to give you the opportunty to unmark the record for deletion if necessary.

4. Press Corr +End to exit your Browse or Edit screen and rethrn to the Control Center screen. "get it back" if you need to by following these instructions to recall the record... 


\section{Deleting and Recalling Records, cont'd}

To recall a record marked for deletion:

1. While in the Browse or Edit screen of the appropriate database, highlight the record you are planning to recall. Note that the Del indicator will be displayed in the Status Bar at the bottom of your screen for each record that has previously been marked for deletion.

2. Press Alt + B to access your Browse or Edit screen's Records menu.

3. Highlight the Clear deletion mark option and press Enter - Note now that the Del indicator has been removed from the Status Bar at the bottom of your screen.

4. Press Ctrl End to exit your Browse or Edit screen and return to the Control Center screen.

5. While in the Browse or Edit screen of the appropriate database, highlight the record you are planning to recall.

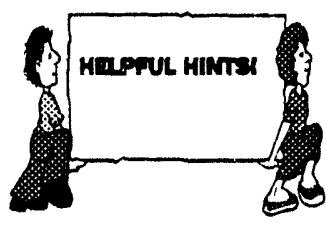

As an alternative to accessing the Records menu to mark and recall (unmark) records, you can press Ctil $+U$. You'll see that pressing $(\mathrm{Ctr}+U$ once will mark the current record for deletion (note again the Del indicator in the Status Bar). Pressing $C$ trl $+U$ again while on the same record will unmark it. The Del indicator will no longer be displayed in the Status bar for that record.

STEP 2: To permanently remove marked records:

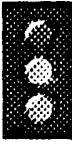

CAUTION! Do not proceed with this step until you are absolutely, positively sure that you want to permanently remove the marked records from your database!

1. While in the Browse or Edit screen of the appropriate database, press Alt + to choose the Organize menu.

2. Highlight the Erase marked records option and press Enter -

3. Choose $Y$ es to confirm the permanent deletion of any marked records.

4. Press Ctrl + End to return to the Control Center screen

$\Rightarrow$ Special Note: Records are removed from ABASE IV database files by a process known as "packing." Packing permits disk space previously used by a database file to be reclaimed when the file is closed. This procedure may take a while, particularly in large database files. So, try to avoid packing your database too frequently. 


\section{Searching for a Specific Records}

You can quickly move to a specific record that you have previously entered in your database file.

1. While in the Browse or Edit screen of the appropriate database, press Aitt $+G$ to display the Go To menu. Highlight and press Enter $\square$ to select one $\mathrm{of}$ the following options:

\begin{tabular}{|l|l|}
\hline Option.. & Description.. \\
\hline Top record & Move to the first record in the database. \\
\hline Last record & Move to the last record in the database. \\
\hline Record number & Move to the record number you specified. \\
\hline Skip & $\begin{array}{l}\text { Jump forward or backward a specified number of records. To move forward, enter a positive } \\
\text { number. Negative numbers will skip backwards. }\end{array}$ \\
\hline Index key search & $\begin{array}{l}\text { If an index exists, cursor will move to each record containing the character string specified. } \\
\text { (Read more about indexed files in ORGANIZING YOUR DATA, later in these notes.) }\end{array}$ \\
\hline Forward search & $\begin{array}{l}\text { Move forward from the current record pointer position to the character string specified. } \\
\text { Your cursor must first be placed in the field you are conducting the search in before } \\
\text { executing this command. }\end{array}$ \\
\hline Backward search & $\begin{array}{l}\text { Move backward from the current record pointer to the character string specified. As with the } \\
\text { Forward search option, your cursor must first be placed in the ficld you are conducting the } \\
\text { search in before executing this command. }\end{array}$ \\
\hline Match capitalization & \begin{tabular}{l} 
When this toggle is sel to Yes, your character string searches will be case sensitive \\
\hline
\end{tabular}
\end{tabular}

2. If you have selected the Record number or S'kip options, type the appropriate number when prompted and press Enter

$-o r-$

If you have selected the Index key search, Forward search or Backward search options, type the character string or the value you would like to find and press Enter

3. The record pointer will automatically (jo To the requested record.

4. Press Cirl + End to return to the Control Center screen.

$\rightarrow$ Special Note: If there is no match for your search criteria, your record pointer will be moved to the end of the file and the EOF indicator will he displayed in the Sitatus Bar at the bottom of your screen.

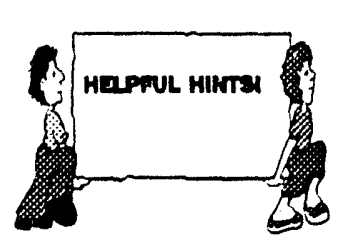

When using the Forward and Backward Search options in the Go To menu, you can use the Find Next function key (Shift + F4 $)$ to automatically move to the next occurrence of the most recently entered search string. Shiff $+F 3$, the Find Previous function key, will move the record pointer backward to a previous occurrence of the most recent search string. 


\section{CLOSING A DATABASE}

dBASE IV provides many important safeguards against accidental loss or damage to data. However, it cannot protect your data against unforeseen occurrences (sudden power surges sometimes caused by electrical storms, for example, that may damage your data.) Therefore, it is important to remember that you should leave databases open only as long as you are working with them. Closing a database greatly reduces the risk of damage to the information within it.

1. At the Control Center screen, highlight the open database file you would like to close - the file's name should appear above the horizontal line in the Data panel - and press Enter

2. Select the Close file option.

\section{QUITTING DBASE IV}

Whenever you have completed your dBASE IV work session, you should exit the program properly. If, for some reason, you have forgotten to close your files, the dBASE IV quit operation will close them for you!

1. At the Control Center screen, press Alt + E to access the Exit menu.

2. Highlight its Quit to DOS option and press Enter - to select it.

$\Rightarrow$ SPECIAL NOTE: If you select "Exit to dot prompt" from the Exit menu, the Control Center screen will be cleared and the dBASE dot prompt (.) will appear at the lower left corner of the screen. You can type QUIT at the dot prompt and press Enter - to exit to the DOS prompt or, remember...you could also type ASSIST and press Enter $\rightarrow$ to return to the Control Center screen. 


\section{WHY ORGANIZE?...AN O JERVIEW}

Most often, data is entered into a database in no specific order. For example, if you were to create a database to hold the names and mailing addresses of your friends, you wouldn't necessarily organize your data in zip code order before entering the informatio 1 in your database. It's important to know that dBASE IV has the capability to do that task for you! Randomly entered data can be organized in a variety of ways according to your exact specifications. Why would you want to rearrange the data in your database? For the same reason you organize the files in your office file cabinet...to make it easier to find things!

dBASE IV offers two methods for organizing your database files...sorting and indexing. The indexing function is the more powerful and functionally sophisticated method and is, therefore, more commonly used. Here's why:

When a database is sorted, a duplicate copy of the database is created and physically rearranged. These two files take up twice the space on the designated disk

Indexed databases, on the other hand, keep track of the desired order of the records without physically rearranging them. A "tag" file is created when a database is indexed. Unlike a sorted database, this tag file does not contain a copy of the entire database. Rather, it contains information that is used to display your original database in the order you specify without actually moving the records.

\section{Kev Fields}

Whether indexing or sorting your database, you'll have to define a key field so that dBASE IV knows just what field you would like to order your file by. Here's an example... suppose you have created a database that contains the following information:

\begin{tabular}{|l|l|l|}
\hline Firstname & Lastname & Department \\
\hline Daffy & Duck & Iluman Resources \\
\hline Porky & Pig & Marketing \\
\hline Bugs & Bunny & Iluman Resources \\
\hline Mickey & Mouse & Public Relations \\
\hline Minnic & Mouse & Marketing \\
\hline
\end{tabular}




\section{Key Fields, cont'd}

If Department is defined as your key field when you index or sort your database, the resulting display may look like this:

\begin{tabular}{|l|l|l|}
\hline Firstname & Lastname & Department \\
\hline Daffy & Duck & Human Resources \\
\hline Bugs & Bunny & Human Resources \\
\hline Porky & Pig & Marketing \\
\hline Minnie & Mouse & Marketing \\
\hline Mickey & Mouse & Public Relations \\
\hline
\end{tabular}

Notice that the records have been arranged to display the Departments listed alphabetically. You can also index or sort your database on multiple fields! Suppose, for example, you still want to arrange your records by Department but, you also would like to display the employees alphabetically by Lastname within each department. A second field can be used as a "tie-breaker" when the same entry occurs in the first key field. In the following example, Department has been defined as the primary key field and Lastname has been additionally defined as a secondary field:

\begin{tabular}{|l|l|l|}
\hline Firstname & Lastname & Department \\
\hline Bugs & Bunny & lluman Resources \\
\hline Daffy & Duck & lluman Resources \\
\hline Minnie & Mouse & Marketing \\
\hline Porky & Pig & Marketing \\
\hline Mickey & Mouse & Public Relations \\
\hline
\end{tabular}

Notice now that the departments are still alphabetically listed but now, the employees last names are correctly alphabetized within each department!

Read more about arranging your database with multiple field expressions in, Creating Complex Indexes in the INDEXING A DATABASE section of these notes. 


\section{SORTING A DATABASE}

As previously mentioned, when a database file is sorted, the original database remains untouched while a second copy of the entire database is created with the records physically rearranged to match the sort criteria you have specified. Important... Once a sorted database file is created, any change made to the original file is not made to the sorted file (and vice versa!) You must, therefore, maintain two separate databases. To sort your database:

1. At the Control Center screen, highlight the database file you would like to sort in the Data panel and press the Data function key, F2.

2. While in either your Browse or Edit screen, press Alt + Oto access the Organize menu.

3. Highlight Sort database on field list and press Enter - An overlay box will appear in which you can enter the field order for the sorted file.

4. Type the desired primary key field name in the Field order column to sort by

- or -

press Shiff $+F 1$ to display a "pick list" of the available fieids in the current database to choose from. Just use your arrow keys to move through the list until you get to the desired field and press Enter - .

5. The key field you have chosen will appear in the first position in the Field order column. Press Enter $\square$ to move your cursor to the Type of sort column and press Spacebar until you cycle to the desired type...

\begin{tabular}{|l|l|l|}
\hline Type... & Example... & Description... \\
\hline Ascending ASCII & $0 \ldots 9 ; \wedge \ldots L ; \mathrm{a} \ldots Z$ & Case sensitive \\
\hline Descending ASCII & $z \ldots a ; Z \ldots \wedge ; 9 \ldots 0$ & Case sensitive \\
\hline Ascending dictionary & $0 \ldots 9 ; \wedge a \ldots . Z$ & Not case sensitive \\
\hline Descending dictionary & $2 Z \ldots a Z ; 9 \ldots 0$ & Not case sensitive \\
\hline
\end{tabular}

6. [Optional Step] If you would like to sort by multiple fields, press Enter - to move to the next available line in the Field order cclumn and repeat steps 4 and 5.

7. Press Ctril End when you are finished defining your sort fields. You will be prompted to enter a name for the newly sorted file. Type the name and press Enter - . (You can also, optionally, type a brief description of this new database and press Enter $\square$.)

The sorting process will begin. This may take a while, particularly if you have a large amount of data in your database file. Remember... a new database file will be created at the completion of the sort. The original database file will remain the current file. If you would like to access the newly sorted file, you'll have to return to the Control Center screen and select it from the IData panel. 


\section{Other Sort Information}

The first field listed in your sort list is the Primary Key. The second field name listed is the Secondary Key, and so on.

D A database file can be sorted on a combination of up to 10 fields.

- You cannot sort on memo or logical field types.

Y You cannot have duplicate field names in the sort list.

Mixed data types can be sorted (character, numeric and/or date fields). You'll see later that this cannot be done automatically when indexing databases.

\section{NDEXINGI DATABASE}

Why is indexing the preferred method of organizing your database file? Because, it is the most flexible and efficient way to order the display of your records. An index directs your display screen to show your data in a particular order instead of the order in which they were originally entered in the database. As mentioned in our overview, the index does not actually rearrange the records in the file on your disk. The index only causes them to appear rearranged on your screen.

Indexes associated with a specific database are stored in a file with an MDX extension. The filename will be the same as the .DBF file to which it is associated. This .MDX file contains the names (or "tags") you assign when you create one or more indexes for a database. For example, you may want to view your database alphabetized by last name then, at another time, display your records in zip code order. These two different index "tags" would be stored in one .MDX file. Up to 47 index tags can be created for each database! You need only tell dBASE IV through its menu system just which "tag" to activate at any given time.

One great advantage of indexing over sorting is that whenever you open a .DBF file that has an MDX file associated with it, all the indexes are automatically activated. Therefore, if any changes are made to the original .DBF file, the index tags in the .MDX file are also automatically updated.

$\checkmark$ Special Note: Previous versions of $A B A S E(I I I, I I I+)$ required separate files with .NDX extensions for each index you wanted to associate with a specific. DBF file. To maintain compatibility with these earlier versions of the product, $A B A S E I V$ will allow you to activate these. NDX files using its menu system but, to create these individual. NDX files in $A B A S E I V$, you must access its dot prompt (.) and use the Index (In command.

dBASE IV offers two ways to create an index. While the "Easy" way is, indeed, fast and simple, it offers little flexibility in structuring your index in a specific way. The Organize menu, on the other hand, will allow for the creation of more complex multiple-keyed indexes. 


\section{Creating a Simple Index...The "Easy" Way}

1. At the Control Center screen, highlight the database file you would like to index in the Data panel and press the Database Design function key, Spacebart + F2 .

2. The Organize menu will be automatically opened. Press EsC to close it and reveal the Database Design screen.

3. Press the Tab key to move your cursor to the Index column and press the Spacebar bar to toggle on a $Y$ es on any field(s) for which you would like to create an index tag. When you toggle on Yes to create an index on a field, the index tag is automatically given the same name as the associated field. Remember...the names and information pertaining to these index tags are maintained in your database's .MDX file which is created as soon as you designate even one field to index on.

4. Press $\mathrm{Ctr}+\mathrm{End}$ when you have finished designating your database index tags and return to the Control Center screen.

$\rightarrow$ Special Note: You can create simple index tags any time the Database Design screen is available. See Part II of these notes, and refer to the sections entitled, Creating a Database and/or Modifying the Database Structure.

$\rightarrow$ Special Note: When you use the Database Design screen method to create an index, the index is automatically created in ascending $A S C I I$ order. To index a file in descending order, you'll have to use the Organize Menu to create your index.

\section{Creating a Simple Index through the Organize Menu}

1. At the Control Center screen, highlight the database file you would like to index in the Data panel and press the Data function key, $F 2$.

2. While in either your Browse or Edit screen, press Alt +0 to access the Organize menu.

3. Highlight its Create new index option and press Enter $\square$.

4. A sub-menu will appear:

- Name of index: Highlight this option and press Enter to type a name for your index tag. Index names can be up to 10 characters long. As noted previously, when you create an index using the "Easy" method, an index tag is given the name of its associated field. It may be helpful when creating a simple index to continue this idealogy and give the index tag name the same name as the field you are planning to index on. Press Enter $\square$ when you have entered a name for your index to proceed to the next option in this sub-menu. 


\section{Creating a Simple Index through the Organize Menu, cont'd}

- Index expression: Highlight this option and press Enter $\square$ to define the field you would like to index the file on. You can just type the name of the field, if you know it...

-or -

Press Shift $+F 1$, the Expression Builder key, to display a "pick list" of field names (and operators) to choose from. Press Enter $\downarrow$ when you have highlighted the appropriate field to move it into the Index expression line in the sub-menu. Press Enter - once again to move your cursor to the next option in the sub-menu.

- FOR clause [OPTIONAL STEP]: Use this option only if you want your index to apply to selected records in the database. For example, if your database lists all of the departments in your entire company but, you want the index to list only those employees in the Marketing department, you can restrict the index to just those people. Restricting the index has the same effect as hiding records that do not meet the condition specified. When the index is active, only those records that meet the condition are displayed on the screen.

To set a condition in the FOR clause option, you must reference the field that is to be restricted, indicate an operator (greater than $>$, less than $<$, equals $=$, does not equal $<>$, for example) and specify the condition. You can just type in the field name, operator and condition here or, again, use the Shift + F1 function to display a "pick list" of field names and operators. So, using the example previously noted to restrict the index to only those records of employees in the Marketing department, the FOR clause line may read something like, DEPARTMENT="Marketing". Quotation marks must be used only on character fields. Numeric fields don't need any punctuation around them (for example, SALARY=25000). If you are restricting a date field, enclose the date in braces, eg., HIRE_DATE $=\{08 / 15 / 95\}$.

See PART V, USING QUERIES TO SEARCH DATABASES, to find out more about specifying conditions and using relational operators.

- Order of index: Specify whether the index should be in ascending or descending order. While this option is highlighted, just press the Spacebar bar to toggle the order between ascending or descending. The default is set as ascending order.

- Display first duplicate key only: This option controls whether records with duplicate index values are displayed once per record (when set to the default, $N o$ ) or displayed only once (when set to Yes). Again, the Spacebar bar acts as a toggle between the two available options when Display first duplicate key only is highlighted.

5. Press Ctr + End to save and activate the index you have just created.

When you Browse your database, it should appear in the order specified by the index you've created. 


\section{Creating a Complex Index}

In addition to creating simple indexes, you can also create complex indexes that use multiple levels of indexing. For example, suppose you would like to display your database in alphabetical order by department. Then, you want each employee listed alphabetically by last name within each department. And, of course, if there is more than one employee with the same last name, the first names should also be listed alphabetically. We've just built a complex index expression that could be defined as: DEPARTMENT + LASTNAME + FIRSTNAME, for example. The initial (or primary) criterion is the field name listed farthest to the !eft.

1. Press Alt +0 to access the Organize menu.

2. Highlight and select the Create new index option.

3. Enter a name for the index as noted in Step \#4 of Creating a Simple Index.

4. Highlight the Index expression option and press Enter - Type in the complex expression as required (for example, DEPARTMENT+LASTNAME+FIRSTNAME). Keep in mind that each of the field names included in your complex expression must be connected with the plus $(+)$ sign. You could also use the Expression Builder to help you create the index expression. Press Shift $+F 1$ to display a "pick list" of field names, operators $(=,<,>$, and., or., etc. $)$ and dBASE functions.

5. Define the Order for index and Display first duplicate key only options as required.

6. Press $\mathrm{Ctrl}+$ End to create and activate the complex index.

IMPORTANT: If the fields in the index expression are not the same type, a dBASE conversion function must be used to formulate a valid expression. The fields noted in the example above, DEPARTMENT, LASTNAME and FIRSTNAME were all character fields. You could not, for instance, create a complex index expression using fields like DEPARTMENT+SALARY since a field holding salaries would most likely be numeric. One of dBASE's many functions is the STR() function. Used properly, it will convert a numeric field type to a character field type for indexing purposes. The correct expression would read: DEPARTMENT+STR(SALARY). dBASE IV functions provide the ability to manipulate data and convert values. They are most often used when dealing with more advanced dBASE options. A brief listing of some of the more frequently used dBASE IV functions is available in Appendix B, BASIC DBASE FUNCTIONS. 


\section{To Choose a Different index}

You may want to activate an index that was previously created instead of using the current index:

1. Press Alt $+\bigcirc$ to open the Organize menu.

2. Highlight and select the Order records by index option. A list of active index tags will be displayed.

3. Highlight the index tag of your choice and press Enter $\square$. $\rightarrow$ Special Note: You can also select "Natural Order" from the list of active index tags if you would like to display your data in the original order it was entered.

4. If you are on the database design screen, press the F2 Data key to display your records in order of your newly selected index.

\section{To Remove a Previously Created Index}

1. Press Alt $+\square$ to open the Organize menu.

2. Highlight and select the Remove unwanted index tag option.

3. A list of index tags previously created will be displayed. Highlight the index tag you would like to delete and press Enter -4 .

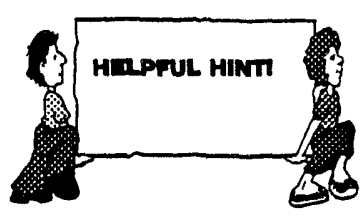

dBASE III+ users beware...In dBASE IV, an .MDX file that may have been previously created will be automatically opened whenever its associated database is used. Therefore, whenever you make any changes to the database (add, delete, edit records) the associated .MDX file and all index tags contained within it will also be updated. This is in sharp contrast to earlier versions of dBASE that necessitated special commands for you to activate individual .NDX files that may have been previously created to ensure that they would be updated whenever the main database (.DBF) file was updated. If you are using .NDX files that were created in dBASE IV or earlier versions of dBASE, it's important to remember that the same rules apply. Make sure you activate them through the dBASE IV Organize menu before making any changes to your database.

\section{Searching for Records}

If the data you are looking for is part of an index expression, you can do an Index Key Search to help locate the record. You could, for example, quickly and easily find the record that contains the employee whose last name is Clinton as long as the index tag containing the field holding the databases' last name's is the current and active index. 


\section{Using an Index Key:}

1. At the Control Center screen, highlight the database file you would like to search in the Data panel and press the Data function key, F2.

2. Press Alt +0 to open the Organize menu and highlight and select the (Order records by index option.

3. Select the appropriate index tag that will correspond with your intended search criterion.

4. Press Alt $+G$ to open the Go To menu.

5. Highlight and select the Index key search option. A prompt box will appear:

\section{Enter search string for}

[The name of your selected index tag will appear here]:

Enter the appropriate search string after the colon (:) and press Enter - . The highlight will move to the record containing the first instance of the search string.

Some Index Key Rules:

* Record searches are case-sensitive. If you want to find a record without regard to its capitalization, make sure you set the Match capitalization option to No in the Go To menu before doing your search.

* An index key search searches for matches from the left to the right of the string entered. For example, if you were looking through a database indexed by state for New York and you entered just the word New as your search string, the resulting search may also find New Jersey and New Hampshire. Enter full and comprehensive search strings to find exact matches.

* You cannot use wildcards (* and ?) in a search string. They are interpreted literally as asterisks and question marks. 


\section{DBASE IV BASICS PART V \\ QUERIES: FILTERING AND SEARCHING YOUR DATABASE}

More often than not, you will find a need to look at just a subset of your database file rather than all of its records. dBASE IV provides a utility to easily select and display only those records that meet a specific criteria. This data extraction and display procedure is commonly known as filtering. To see data from only certain records in your database, you query, or ask, dBASE IV to search the entire database but display only those records that meet a certain condition.

To query a dBASE database, you must first specify the limiting criteria. dBASE IV will ignore any records that don't meet the conditions you have entered. Those that do meet the condition(s) are displayed on your screen.

\section{THE QUERY DESIGN SCREEN}

There are two types of queries you can create in ABASE IV: view queries and update queries.

- View queries provide a view, or a partial picture, of the data contained in your database file. View queries allow you to select certain records, display specific fields or combine data from more than one database file. Use view queries to display data, enter data, rearrange fields in a different order and/or limit the fields to be displayed. This tool is known as Query By

Example. QBE is a tool that can be used to refine your searches so that as few as one record can be found among thousands! $2 \mathrm{BE}$ also provides you with the ability to restructure fields, perform calculations and sort your data. View queries are also used as a basis for creating forms and reports. When you have completed using a view, it no longer exists in your computer's memory. However, you can save the query that defined the view so that it can be used at a later time.

- Update queries provide a way to make a broad change to your database file. Add, delete or edit records in your database that meet the conditions specified in an update query. Update queries are also commonly used to group records to be deleted or undeleted and/or replace data in certain fields.

We'll use the following structure of a hypothetical database named, limployee. $d b f$ throughout our exploration of the Query tool:

\begin{tabular}{|r|l|l|r|r|c|}
\hline Num & Field Name & Field Type & Width & Dee & Index \\
\hline \hline 1 & LASTNAME & Character & 25 & & $Y$ \\
\hline 2 & FIRSTNAME & Character & 15 & & $Y$ \\
\hline 3 & DEPARTMENT & Character & 15 & & $Y$ \\
\hline 4 & SALARY & Numeric & 7 & 2 & $N$ \\
\hline 5 & HIIRE DATE & Diate & 8 & & $\times$ \\
\hline
\end{tabular}


Both view and update queries are created in the same Query Design screen. To access it...

1. [OPTIONAL STEP] In the Control Center, highlight the database file that you would like to query in the Data panel and press Enter - Select the Use file option.

2. While still in the Control Center, select the <create> marker in the Queries panel. dBase IV will display a screen that looks something like this:

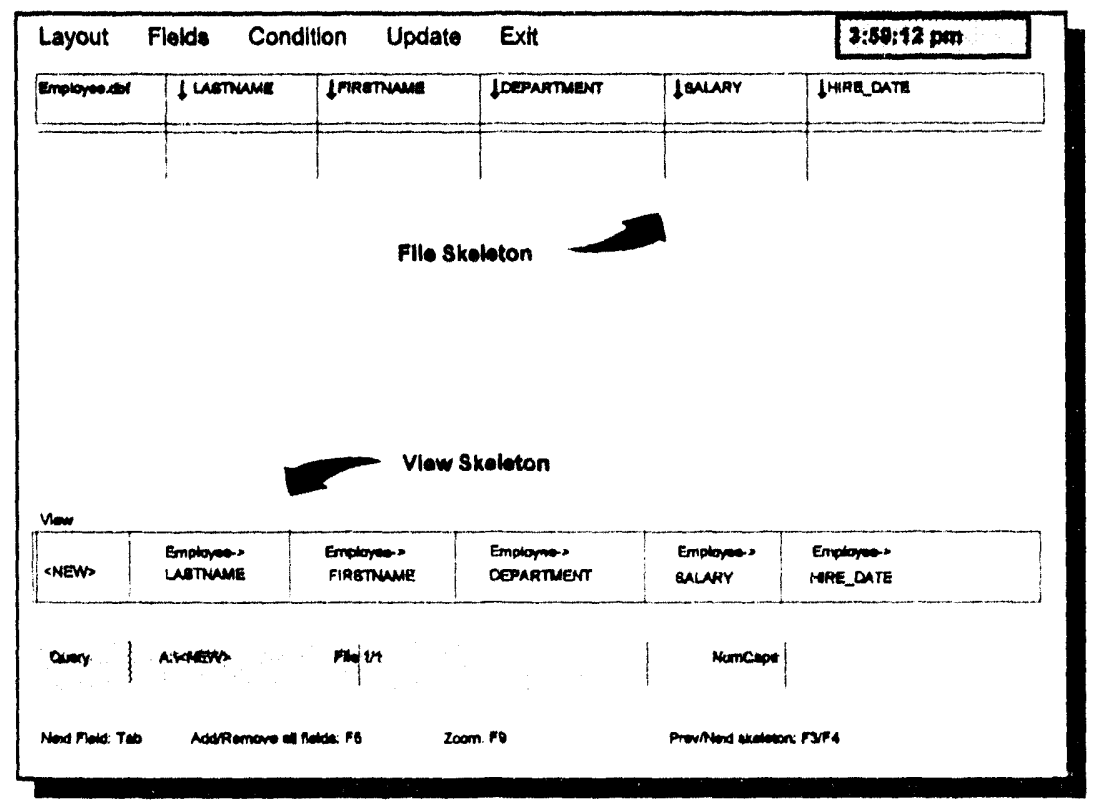

As with other work areas in dBASE IV, the Query Design screen displays a menu at the top offering relevant Query options. The Status and Navigation bar appears at the bottom of the Query Design screen

A File Skeleton appears along the top of the screen and lists the name of the current database, (in this case, limp'ryee. (bf) and its associated field names. If all the field names don't appear on the screen, you can press the Tab key to scroll to the right. Shiff + Tab will scroll you back. The File Skeleton area is used to specify conditions dBASE IV uses to search your database. It can also be used to sort or index the database, create summary fields and group the data as required. A down arrow marker in front of a field name in the lile Skeleton indicates that the field has been included in the View Skeleton.

The View Skeleton is used to specify which fields will be displayed on screen when a query is processed. Initially, all fields contained in the file skeleton are in the view skeleton. But, you can remove fields from the view skeleton or move them to different locations to change the appearance of the data as it is displayed when the query is processed. You can also press the Tab key in this area to scroll to the right and see additional fields that may not fit on this initial screen.

In short, the File Skeleton area is used to define the condition(s) dBASE IV uses to search your database while the View Skeleton is used to specify the fields that will be included when the query is processed and displayed on your screen.

$\Rightarrow$ SPECIAL NOTE: The F4 key acts as a toggle switch to move your cursor between the lite and View skeletons. 


\section{CREATING A VIEW QUERY}

\section{Working with the View Skeleton...Specifying the Field Display}

As previously noted, when a database has been previously selected in the Control Center and the Query Design screen is accessed, all the fields in the active database are displayed in both the File and View Skeletons. But, you can add, delete or move the fields in the View Skeleton to meet your specific display requirements.

\section{To Delete Fields from the View Skeleton:}

1. If the cursor is not already in the View Skeleton, press F4.

2. Use the Tab, Shift $+\mathrm{Tab}$ and/or arrow keys to highlight the field you would like to delete from the View.

3. Press Alt $+F$ to access the Fields menu and select the Remove Field from View option

$$
\text { -or- }
$$

just press $F 5$ to remove the highlighted field!

You'll notice that the down arrow indicator (1) preceding the corresponding field name in the File Skeleton has been removed.

IMPORTANT: Keep in mind that you have NOT removed a field and all its relevant data from your database when you remove it from a View Skeleton. You're merely removing the display of the field on your screen once you ultimately process the query

\section{To Add Fields to the View Skeleton:}

1. If the cursor is not already in the File Skeleton, press $\mathrm{F}_{4}$.

2. Use the $\mathrm{Tab}, S$ hift $+\mathrm{Tab}$ and/or arrow keys to highlight the field you would like to add to the View.

3. Press $A$ Alt $+F$ to access the Fields menu and select the Add lield to View option just press $F 5$ to add the highlighted field!

\section{To Move Fields in the View Skeleton}

1. If the cursor is not already in the View Skeleton, press F4.

2. Use the $T a b$, Shift $+T d D$ and/or arrow keys to highlight the field you would like to move within the View.

3. Press $F$ to select the field. (To move more than one at a time, use Tab and Shift + Tab to extend the selected fields to the right or left.) Press Enter -

4. Press the move key, F7.

5. Use Tab and/or Shift T Tab to move the selected field(s) to the new location. When the fields are where you want them to reside, press Enter $\square$ 


\section{Working with the File Skeleton...Specifving a Ouery Condition}

1. In the Query Design screen, use your Tab, Shift $+\mathrm{Tab}$ and/or any other appropriate arrow keys to position the cursor in the field noted in the File Skeleton for which you want to specify a condition.

2. Type the condition. In the illustration to the right, I'm looking for all of the employees in the database who are in the Marketing department.

3. Once the condition has been specified, press the F2 Data key. dBASE IV

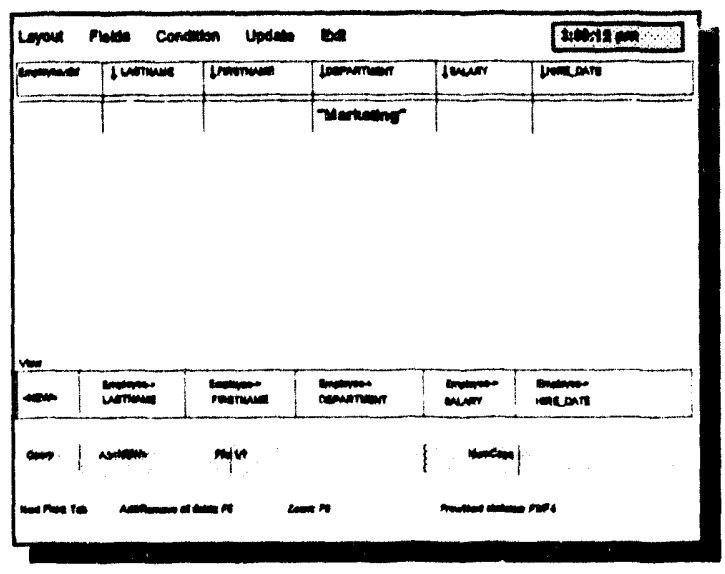
initializes the search and displays those records that meet the condition. Press Shift $+F 2$ to return to the Query Design screen.

\section{Search Entry Conventions}

Character-type data searches must be enclosed in quotation marks, "like this"

Date-type data searches must be enclosed in curly braces, $\{08 / 15 / 94\}$, like this.

Numeric-type data searches need no punctuation marks.

Logical-type data searches require only a true or false search value entered as either .T. or .F. (those preceding and ending periods are important.)

Memo-type data searches cannot be conducted through the Query Design screen.

\section{Using Relational Operators in Searches}

While you may often need to find a specific value or string in your database, you may also find a requirement to search for records above or below a certain value. For example, suppose you would like a listing of all those employees who were hired after June 1, 1994. You must use relational operators to specify this type of condition. The entry would be typed in the HIRE_DATE field noted in the File Skeleton as $>\{06 / 01 / 94\}$. Here's a brief listing of frequently used relational operators:

\begin{tabular}{|c|c|c|}
\hline Operator & Name & Description \\
\hline , & greater than & All records whose lited value is greater than the specelied search value \\
\hline 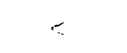 & less than & All records whose field value is less than the search value \\
\hline$=$ & equal & All records whose field value equals the search value \\
\hline$>$ or $\#$ & not squal & All records whose field value is not equal to the search value \\
\hline - : & greater than or equal to & All records whose field value is greater thath or equal to the scarch value \\
\hline$\therefore$ & less than or equal to & . Nll records whose field value is less than or equal to the search value. \\
\hline like & pattern match & Nlows wild card (") searches \\
\hline
\end{tabular}




\section{Searching with Wild Cards}

You can use the asterisk $\left({ }^{*}\right)$ wildcard to find records that have character-field values matching a condition you specify BUT you must preface your condition with the "Like" relational operator. For example, if I wanted to find all of the employees whose last names began with the letter B, I would have to enter Like " $B$ " under the LASTNAME field in the File Skeleton.

\section{Searching for Values Within a Range}

Often, you need to display records whose values fall between two specific values. You can specify a "from-to" range very easily in your query. Just enter the statement that specifies the lower end of the range followed by a comma and a separate statement indicating the higher end of the range. The condition entered in the SALARY field in the illustration to the right would display only those records whose salaries fall between $\$ 50,000$ and $\$ 75,000$ when the F2 Data key was pressed to process this query.

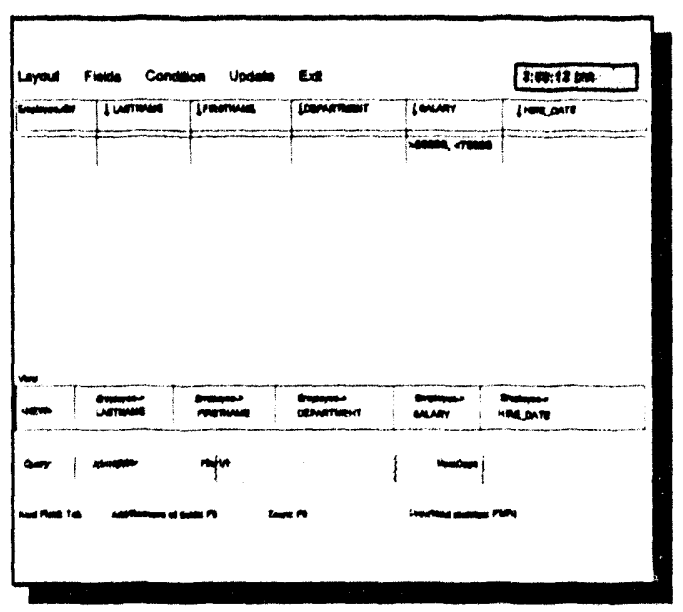

\section{Multiple (AND, OR) Condition Searches}

dBASE IV provides a mechanism for you to combine searches in a query. You may have a requirement, for example, to search for more than one value in a field. Or, perhaps you'll need to process records that meet conditions in more than one field. Here's how it works.

To search for values in two different fields.

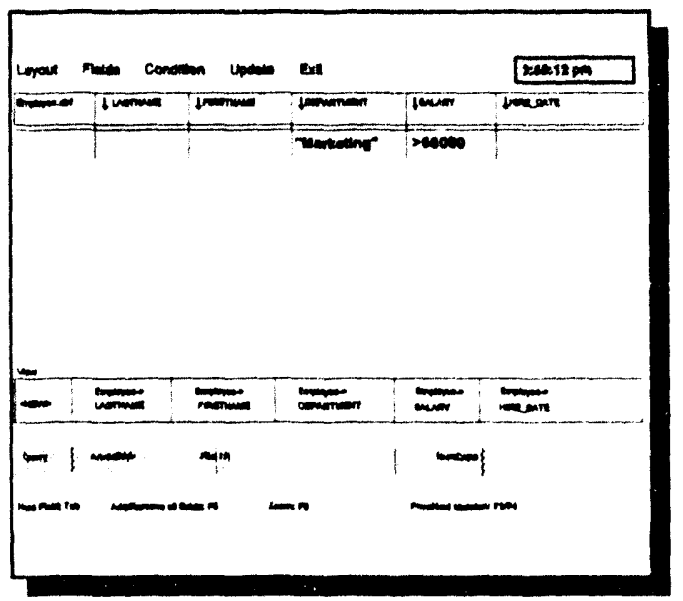

When separate conditions are placed in separate fields but, on the same line in the lile Skeleton, the search is considered to be what is known as an $A N D$ search. dBASE IV will test each record in the database to see whether the first value and the subsequent values are met. For example, the illustration at left displays conditions that, when met, will display records of those employees who are in the Marketing department and who have salaries that are greater than $\$ 50,000$. 


\section{Multiple Condition Searches, cont'd}

On the other hand, when the two conditions are placed on separate lines in the File Skeleton the search is considered to be an $O R$ search. For example, this illustration would display all the records of those employees who are either in the Marketing department or have a salary greater than $\$ 50,000$

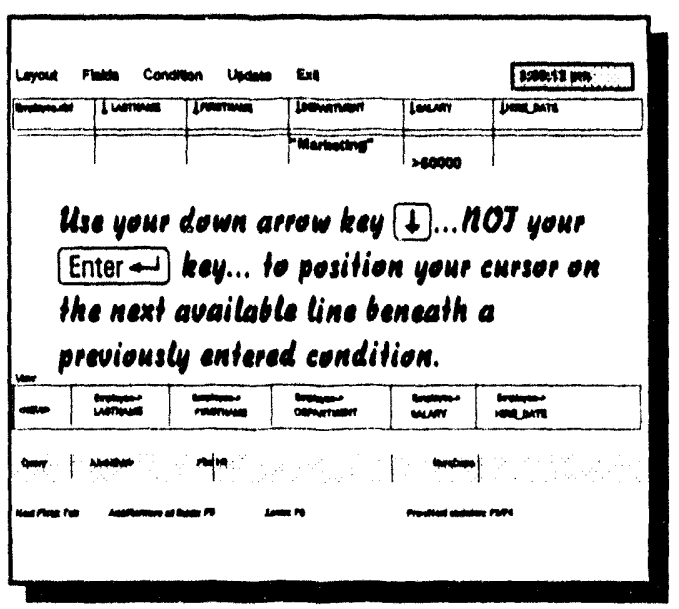

Searching for multiple conditions in the same field...

$A N D, O R$ rules cannot be applied in the same field as they are in multiple fields. Here's why..

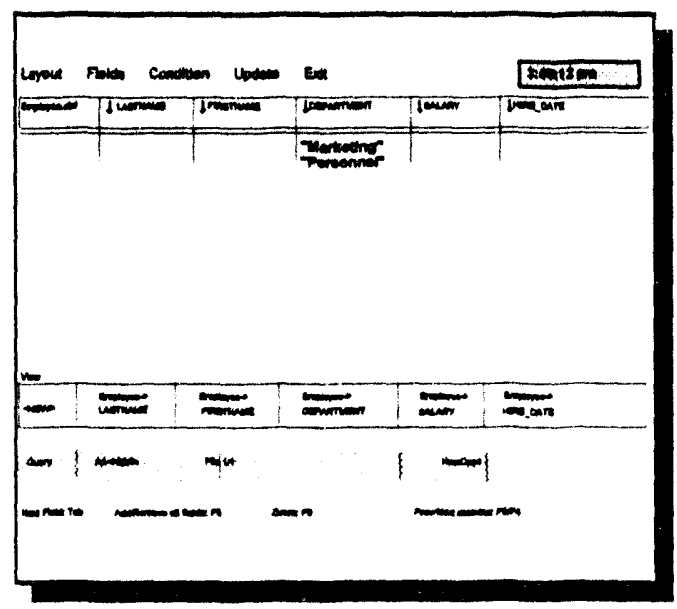

If you were to search for one value AND another in the same field by entering the conditions on the same line in the appropriate field in the File Skeleton, the results may not be what you had anticipated. In the illustration to the right, the search conditions, $\{09 / 07 / 91\},\{03 / 05 / 94\}$ have been entered under the HIRE_DATE field in the File Skeleton. By placing both criteria on the same line, you would be looking for all those employees hired on September 7, 1991 and March 5, 1994. Can any one employee have two hire dates? No! As a result, when the F2 data key is pressed to process this query, no records would be displayed.
You can search for one value OR another in the same field by simply entering the conditions one under the other in the appropriate field in the File Skeleton.

The search conditions in the illustration to the left would display all the records of employees in either the Marketing or the Personnel departments when the F2 data key was pressed to process the query.

However...

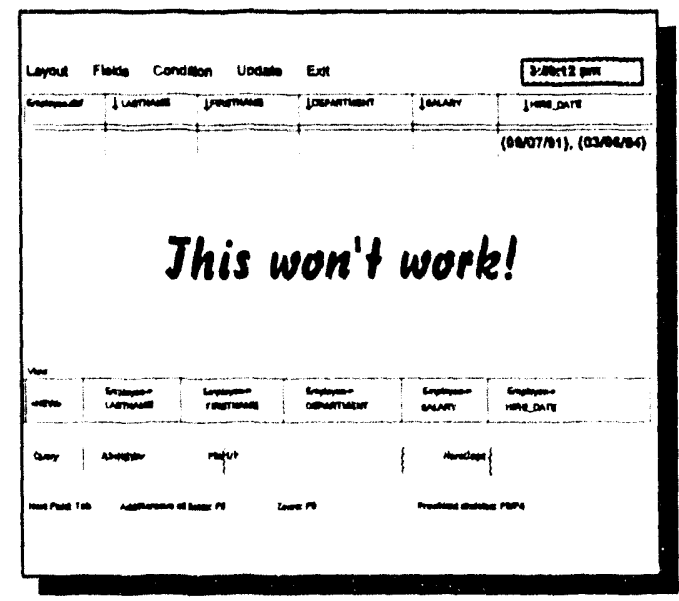




\section{Summarizing Values}

You may not always want to see all the records ihat meet certain search criteria. There may be times when you just want information about the totals of these records. For example, maybe you would want to see the sum of all of the salaries of the employees in your database. Or, perhaps you'd like to calculate the average of the salaries. dBASE IV provides seven summary operators to help you with this function:

\begin{tabular}{|l|l|}
\hline Operator & Qeseriptlon \\
\hline SUM & Adds all values in the ficld and returns the sum \\
\hline AVG & Returns the average value of a field \\
\hline MIN & Returns the minimum value of a field \\
\hline MAX & Returns the maximum value of a field \\
\hline STD & Calculates the standard deviation of a field \\
\hline CNT & Counts the number of records that meet the specified condition \\
\hline VAR & Calculates the population variance \\
\hline
\end{tabular}

Just enter one of these operators in the appropriate field name of the File Skeleton. When you press F2 to process the query and display the data, the only field(s) that will display data will be the field(s) that you have entered the summary operator in. All other fields will be blank. In all summary operations, the value returned is only for records that meet any specified search condition in the query. For example, the illustration to the right would sum the total of all the salaries of only those employees in the Marketing department. If you do not specify a condition, all records are calculated.
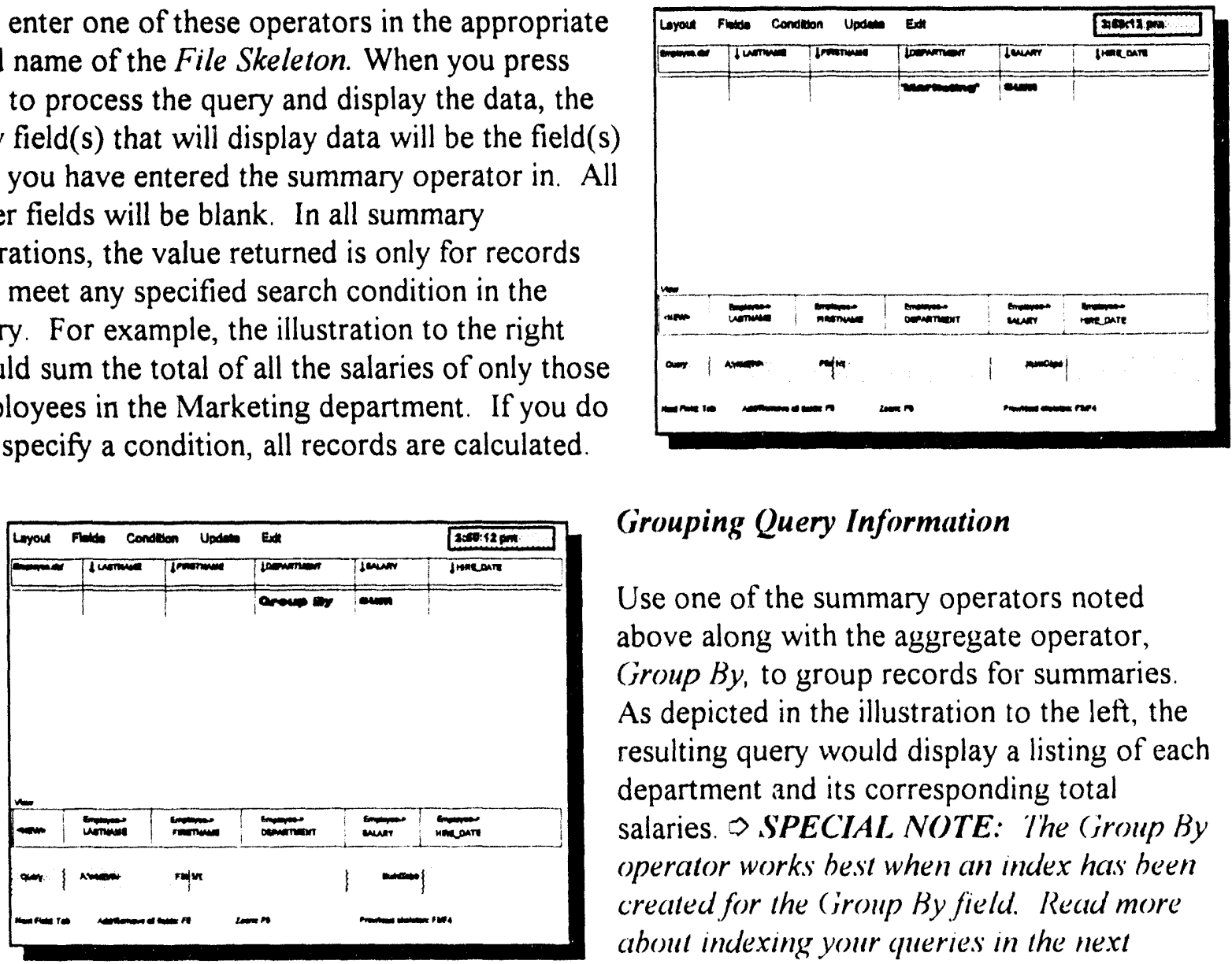

\section{Grouping Query Information}

Use one of the summary operators noted above along with the aggregate operator, Group By, to group records for summaries. As depicted in the illustration to the left, the resulting query would display a listing of each department and its corresponding total salaries D SPECIAL NOTE: The (iroup By operator works best when an index has been created for the (iroup By field. Read more about indexing your queries in the next section. 


\section{Indexing the Query Output}

Display your queries in a specific order by just "turning on" the indexes you may have previously created for them:

1. Press Alt $+F$ to open the Query Design screen's Fields menu.

2. Highlight the Include indexes option and press Enter- to set it to Yes.

Now, take a look at your field names in the File Skeleton. Any field for which you have previously created an index tag will be preceded with an $\mathbf{\Delta}$ symbol indicating that the field is indexed in ascending order or an $\boldsymbol{\nabla}$ symbol, indicating that the field has been indexed in descending order. If you have created a complex index that references multiple fields (LASTNAME+FIRSTNAME, for example) the index will appear as a separate field name at the end of all the other field names in your File Skeleton.

3. Tab to the field you would like to order your query by and press $\overline{A l t}+\mp$ to open the Query Design screen's Fields menu once again.

4. Highlight its Sort on this field option and press Enier to select it.

5. Highlight the type of sort desired and press Enter

When you press F2 to process the query, you'll find it ordered by the index specified. Read more about creating index tags in PART IV, ORGANIZING YOUR DATA.

\section{Using the Condition Box}

The Query Design screen's Condition Box can be used to test each record as a whole instead of testing individual fields in the File Skeleton. The conditions entered in the Condition Box can address more than one field. It is important to note that Condition Boxes require that you enter dBASE expressions that are syntactically correct. Therefore, this utility is often used by more advanced dBASE users familiar with the syntax of its commands. To use the Condition Box:

1. Press Alt $+D$ to open the Query Design's Condition menu.

2. Highlight the Add Condition box option and press Enter $\square$ to select it.

3. Enter the condition of your choice.

4. Press F2 when you are ready to process the query and view the data.

\section{Condition Box Facts to Remember...}

Only one condition box per query is allowed.

Enter your condition by typing it directly into the box or, use the Expression Builder key, Shift +F1 to display your "pick list" of fields, operators and functions

Conditions entered on separate lines in a condition box are treated as $A N D$ conditions.

$\square$ Press the $F 9$ Zoom key anytime you need to expand the Condition Box to display a condition that may exceed the length of the smaller box. Press $F 9$ again to return the box to its normal size. 


\section{Searching Memo Fields with the Condition Box}

Memo fields cannot be searched or filtered via the File Skeleton. However, you can conduct your search on a memo field via the Query Design screen's Condition Box. Suppose, for example, you wanted to find out just who uses the PC software, Lotus 1-2-3 and you have entered this, as well as other information, in a memo field called JOB DUTIES. Here's how you'd enter the condition..."Lotus 1-2-3" \$ JOB_DUTIES.

The $\$$ is an operator that means "included in". This tells dBASE to look in the specified memo field for the character string "Lotus 1-2-3". Only those records that contain this string in the JOB_DUTIES memo field would be displayed when the F2 key is pressed to process the query.

$\checkmark$ SPECIAL NOTE: Condition box searches are case sensitive. Therefore, in the example noted above, LOTUS 1-2-3 would not be found!

\section{Saving a View Ouery}

If you think that you would want to use the same search and/or filter conditions on your database in the future, you can save your query and use it again!

You can save your query without exiting the Query Design screen:

1. Press $A$ Att $+\square$ to select the Query Design screen's Layout menu.

2. Highlight the Save this query option and press Enter - to select it.

3. If you are saving your query for the first time, you'll be prompted to enter a descriptive name for the file. Type it and press Enter - .

$$
\text { -or- }
$$

You can save your query and exit to the Control Center screen.

1. Press CArl + End while in the Query Design screen.

2. If you are saving your query for the first time, you'll be prompted to enter a descriptive name for the file. Type it and press Enter 4 .

When view query instructions are saved, they are placed in the file name you have specified and given a QBE extension. You'll see the name of the query file you have just saved above the horizontal line in the Queries panel when you are returned to the Control Center screen. This indicates that, even though you are no longer in the Query Design screen, the query is current and active. To de-activate it, just highlight its name in the Queries panel, press Enter - and select Close view. Its name will be positioned bencath the horizontal line in the Queries panel. 


\section{Using a Previously Created Query}

To use or modify a query you may have previously created, simply highlight its name in the Queries panel of the Control Center and press Enter - then...

Select Use view to activate the query in the Control Panel

-or-

You can make changes to the query instructions/conditions by selecting the Modify query option.

Display the data that meets the conditions specified within the query by selecting the Display data option.

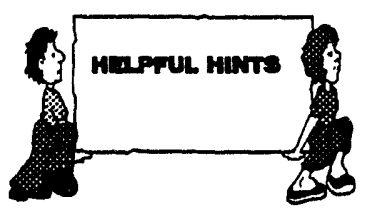

$\checkmark$ If you make any changes in the Query Design screen that you don't want to save, press Alt + E to access the Exit menu and select its Abandon changes and exit option.

$\sqrt{ }$ Highlight query instructions you may want to remove and press $C+r i$. This will delete a previously entered condition in the Query Design screen's File Skeleton.

\section{UPDATE QUERIES}

Update queries are most commonly used to make changes to the entire database, rather than to filter subsets of it as the view query does. Four update operations can be performed:

Replace record(s)

Append (add) data

Mark records for deletion

[ Unmark records for deletion

Update queries are created by first accessing the Query Design screen. Follow the instructions to access this screen as previously noted in the Query Design Screen section.

\section{Replacing Database Values with an Update Ouery}

The Replace Values option enables you to replace the values of all or part of a database with another value. Suppose, for example, in our hypothetical Employee. dbf file (structure noted on the previous pages), everybody is due for a $10 \%$ raise in their salary. We would want to replace the amount noted for each employee in the SALARY field with the current SALARY $+10 \% \ldots$

1. If it is not already in use, select the database from which you'll be replacing records from the Control Center's Data panel.

2. Highlight the <create> marker in the Queries panel and press Enter - .

3. Press Alt $+U$ to select the Query Design screen's Update menu. Select its Specify update operation option. 


\section{Replacing Database Values with an Update Ouerv, cont'd}

4. Highlight the Replace values in option and press Enter - to select it. (You'll notice that this option includes the name of the database (.dbf file) in use in your query.

5. Choose Proceed when prompted that the View Skeleton will be deleted. (Update queries do not display data on screen so, the View Skeleton is not needed.)

6. The word Replace will appear beneath the name of your database in the File Skeleton.

7. Press $\mathrm{Tab}$ to move to the appropriate field in which data will be replaced. (In our example, we would be highlighting the SALARY field.)

8. Enter the replacement value preceded by the with operator. For our example, in the SALARY field, we would enter, with SALARY +.10. Don't forget...this expression is telling dBASE to replace all of the current values in the SALARY fields with the current SALARY value + $10 \%$.

9. [OPTIONAL -BUT VERY IMPORTANT - STEP] Unless you specify a condition before proceeding with the update, the replacement value noted in the File Skeleton will 2. change all of the records in your database. Be careful! You may have a need to replace only a few records. For example, suppose our hypothetical salary raise was being distributed to only those people hired after a certain date. You would have to limit the replacement scope by using a Condition Box before performing the update...

- Press Alt $+C$ to activate the Query Design screen's Condition menu and select its Add condition box option. When the condition box is displayed, enter your limiting condition. Using our example, you would enter something like, HIRE_DATE $>\{08 / 15 / 93\}$

10. Press Alt $+U$ to access the Query Design screen's Update menu once again and select its Perform the update option.

11. When the update is completed, you can press any key, as instructed, to return to the Query Design screen.

12. Press $F 2$ to display the updated information.

\section{Appending Data with Update Oueries}

This urdate utility tool is useful when you are adding records from one database into another and both database structures are not identical. (If the database structures are identical, you can use the Append data from option found in the Append menu in the Data Design screen.)

When you append records, you are adding records to the end of the active database file. The active database is your target file. The database you are taking the records from is your source file. 


\section{Preparing to Append Data}

Before you can append data to one database from another, both the target and source files must be listed in the current catalog. If one or the other database does not appear in the Data panel in the Control Center screen...

1. Press Alt + C to activate the Catalog menu.

2. Highlight the Add file to catalog option and press Enter - to select it.

3. A listing of all previously created dbf files in the current default directory will be displayed

4. Select the required database file.

5. Its name will appear in the Data panel in the Control Center.

\section{Appending the Data}

1. If it is not already in use, select the target database (that's the database you're going to be adding records $t o$ ) from the Control Center's Data panel.

2. Highlight the <create $>$ marcer in the Queries panel and press Enter $\square$.

3. The Query Design screen will appear with the target database file's structure displayed in the File Skeleton.

4. To select your source file, Press $A$ Alt $+\square$ to activate the Query Design screen's Layout menu.

5. Highlight its Add file to query option and press Enter - to select it. This source file will be added to the File Skeleton in the Query Design screen.

6. Press F3 to move your cursor up to the target database File Skeleton.

7. Press Alt $+U$ to activate the Query Design screen's Update menu and select its Specify update operation option.

8. Highlight the Append records to < target filename $>$ option and press Enter $\rightarrow$ to select it. (The name of the database that the records are to be added to will appear in this option.)

9. Choose Proceed when prompted that the View Skeleton will be deleted. (Update queries do not display data on screen so, the View Skeleton is not needed.)

10. The word Append will appear in the column underneath the target database's filename and the word Target will appear above the filename.

11. Type matching example variables in both the target and source files. These example variables tell dBASE IV just which fields in the source file to use. The matching variables placed in the target file tell dBASE IV where to put the data in the records that will be appended to the target file. These variables can be any word you define but, they must match.

12. Press Alt +0 to activate the Query Design screen's Update menu and select its Perform the update to append the records.

13. dBASE IV will execute the query, adding one record to the target database for each record in the source database. A message will appear on your screen letting you know when the update has been completed. To display the target file with its newly added records, just press F2. Press Shift $+F 2$ to return to the Query Design screen. 


\section{Deleting and Undeleting Records}

We've seen previously how you can mark and unmark individual records for deletion (see PART III, USING A DATABASE, Deleting and Recalling Records). Use an update query when you want to mark (or unmark) a large number of records for deletion.

1. If it is not already in use, select the database from which you'll be marking records for deletion from the Control Center's Data panel.

2. Highlight the <create> marker in the Queries panel and press Enter 4 .

3. Press Alt $+\square$ to select the Query Design screen's Update menu. Select its Specify update operation option.

4. Highlight the Mark records for deletion option and press Enter - to select it. (You'll notice that this option includes the name of the database (.dbf file) in use in your query.

5. Choose Proceed when prompted that the View Skeleton will be deleted. (Update queries do not display data on screen so, the View Skeleton is not needed.)

6. Specify the condition a record must meet to be marked in the File Skeleton.

7. Press Alt +0 to activate the Query Design screen's Update menu once again and select its Perform the update option.

8. Press F2 to process the query and display those records that meet the specified condition(s) and display the records that have been marked for deletion.

Follow these same steps to unmark records that may have been previously marked for deletion. Just select the Unmark records option within the Update menu's options.

\section{Removing Records Marked for Deletion}

Once the records have been marked for deletion, they can be erased from the database via the Edit or Browse screens. See the directions previously noted in PART III, Deleting and Recalling Records.

\section{Saving Update Queries}

Update queries are saved just as view queries are saved...

1. Press $A$ Att $+\square$ to select the Query Design screen's Layout menu.

2. Highlight the Save this query option and press Enter to select it.

3. If you are saving your query for the first time, you'll be prompted to enter a descriptive name for the file. Type it and press Enter

You can save your query and exit to the Control Center screen.

1. Press CtrI +End while in the Query Design screen.

2. If you are saving your query for the first time, you'll be prompted to enter a descriptive name for the file. Type it and press Enter - 


\section{Saving Update Queries, cont'd}

When update query instructions are saved, they are placed in the file name you have specified and given a .UPD extension. You'll see the name of the query file you have just saved above the horizontal line in the Queries panel when you are returned to the Control Center screen. This indicates that, even though you are no longer in the Query Design screen, the query is current and active.

DSPECIAL NOTE: Update query file names will be preceded by an * to help you quickly differentiate them from view queries. 
Report generation is an important tool in analyzing and reviewing the information that is contained within your database file. dBASE IV provides a utility to quickly and easily produce printed output of that information. There are two distinct types of reports you can create with dBASE IV: Quick Reports and Custom Reports.

\section{QUICK REPORTS}

The fastest (and absolute easiest) way to create a report is with dBASE IV's Quick Report. This utility will generate a very simple report, using the field names you've created in your database as its column headings. The only "extras" added to the printed output of your data is a Page number and current date at the top of every page in the report.

Each column in a Quick Report will print at least as wide as the designated field width. If a field's name is longer than its width, dBASE IV will make the column wider to accommodate it. All numeric fields are totalled in the last line of the Quick Report. To create a Quick Report:

1. In the Control Center screen, select the database file or the view query file you would like to generate a report for.

2. Press Shift $+F$ to activate the Quick Report menu.

3. The first option, Begin printing, will be already highlighted by default. Just press Enter $\square$ if you would like to print the report immediately..

-or-

Select the View report on screen option to get an on-screen preview of how your printed report will look.

4. dBASE IV will generate some internal programming code to create the report before it actually sends the information to your printer. This may take a few seconds

You may want to use some of these other options in the Quick Report menu to properly adjust your printed output...

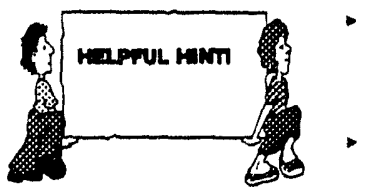

Destination: If you have the availability of more than one printer (and many people using dBASE IV from a network do) you can use this option to select the printer type and destination

Control of printer: Set the text pitch and print quality through this option. In addition, you can direct $\mathrm{dB} \wedge \mathrm{SE} I V$ to eject a blank page before and/or alter a report or eject no pages at all.

- Output options: If you don't want to print the entire report, you can specily a subset of the report by detining beginning and ending pages. Also, change the starting page number and designate the number of copies of the report you would like printed.

- Page dimensions: Set your page length hore. This is an important option because dBASE assumes you are placing 66 lines on a page while most laserjet printers print 60 lines on a page. You may need to change this definition to accommodate your printer type so that page breaks in your report oceur at the proper placement. You can also specify an integer that represents the number of inches of extra margin added to the left edge of your report page and change your line spacing from single to double or triple. 


\section{CUSTOM REPORTS}

The dBase IV Report Design screen will provide the necessary tools to create customized reports. Unlike Quick Reports, Custom Reports will allow you to...

Add an introduction to your report that will be printed on the first page only.

- Create your own page header that will appear at the top of each page of your report.

- Create a page footer that will appear at the bottom of each page of your report.

a Add a report summary that can be used to summarize various fields.

$\square$ Delete and/or re-arrange the display of the columns (or fields).

Create "calculated" fields that display the results of calculations that are based on information contained within the existing fields in your database.

Add other pre-defined system fields that will print the current date, time, page or record number.

- Add column headers that are different from the field names designated in the database.

Draw lines and boxes.

Group relevant data

We'll use the same structure for our hypothetical database, Employee.dbf, when illustrating Custom Report options as was used with our Query file examples:

\begin{tabular}{|r|l|l|r|r|c|}
\hline Num & Field Name & Field Type & Width & Dec & Index \\
\hline \hline 1 & LASTNAME & Character & 25 & & $\mathrm{Y}$ \\
\hline 2 & FIRSTNAME & Character & 15 & & $\mathrm{Y}$ \\
\hline 3 & DEPARTMENT & Character & 15 & & $\mathrm{Y}$ \\
\hline 4 & SALARY & Numeric & 7 & 2 & $\mathrm{~N}$ \\
\hline 5 & HIRE_DATE & Date & 8 & & $\mathrm{~N}$ \\
\hline
\end{tabular}




\section{The Report Design Screen}

1. At the Control Center screen, select the database file or view query file for which you would like to create a customized report.

2. Highlight the <create> marker in the Reports panel and press Enter $\downarrow$ to select it. The following screen will be displayed:

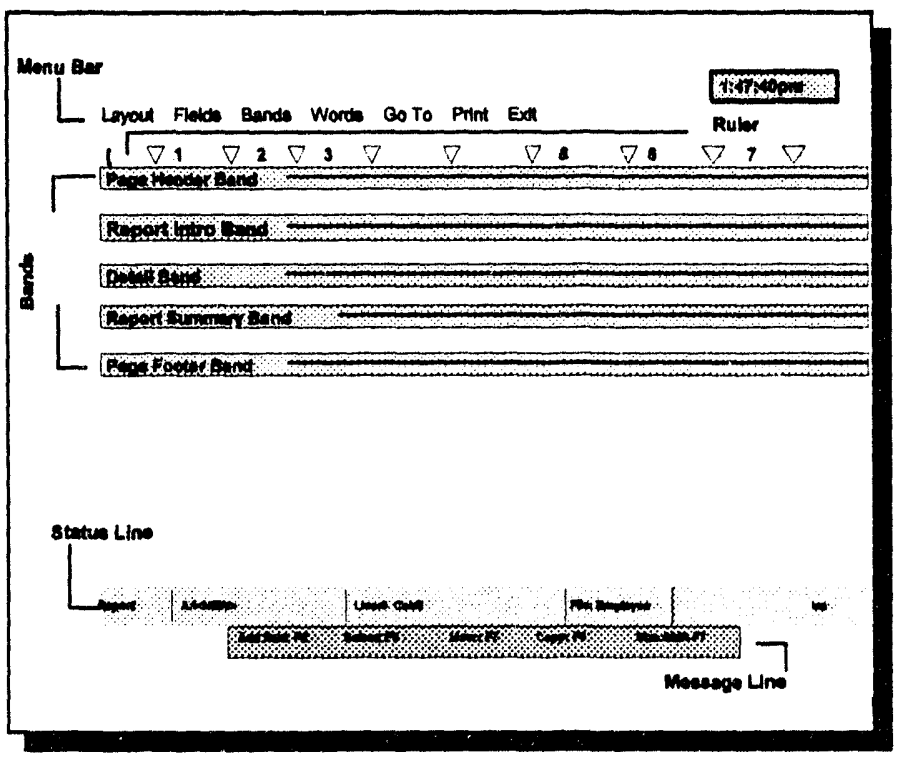

- Similar to other work areas in dBASE IV, the Report Design screen displays a menu at the top whose options can be accessed by typing Alt plus the first character of the desired option.

- A ruler appears beneath the Report Design screen's menu. As your cursor moves through the work area, you'll notice that a highlight will move along the ruler to aid you in judging just where you are positioned in the report. The numbers on the ruler represent "tens" positions while the down arrow symbols represent tab settings. The ruler is primarily used to set your left and right page margins

- The Report Design screen contains five bands. Below the title of each band is a shaded blank space. Depending on just how you would like your custom report to look, text and/or fields are placed in relevant shaded areas. The following table further explains the purpose of each of these bands:

\begin{tabular}{|l|l|}
\hline Page Header Band & $\begin{array}{l}\text { Contains fields and/or text that will print at the top of each page Your report title, a } \\
\text { date/time stamp and/or column headings are usually placed in this band. }\end{array}$ \\
\hline Report Intro Band & $\begin{array}{l}\text { Prints on the first page of your report only after the Page fleader band. More detailed } \\
\text { information about your report may be placed in this band. }\end{array}$ \\
\hline Detail Band & $\begin{array}{l}\text { The fields that you want displayed in the body of the report and any additional descriptive } \\
\text { text is placed in this band. Prints once for cach corresponding record in your data base }\end{array}$ \\
\hline $\begin{array}{l}\text { Report Summary } \\
\text { Band }\end{array}$ & $\begin{array}{l}\text { Prints at the end of each report after the last record printed in the Detail band. This band is } \\
\text { generally used to display summarized data, or totals, of numeric licld data. It is also helpful } \\
\text { when you want to count the number of records in your report. }\end{array}$ \\
\hline Page Footer Band & $\begin{array}{l}\text { Prints at the bottom of each page. Many people use this to display the page number of their } \\
\text { report. }\end{array}$ \\
\hline
\end{tabular}




\section{The Report Design Screen, cont'd}

- The Status Line near the bottom of the Report Design screen is used as it is in other work areas of dBASE IV...the type of screen, report name and path and active related database are displayed. In addition, if your cursor is currently placed inside a band in your report, the band number/total band number is displayed. If your cursor is inside a shaded area beneath a band - where you can place fields and/or text - the appropriate line and column numbers of your cursor position will be displayed.

- The Navigation Line at the very bottom of the screen will remind you of function keys available in the Report Design screen...

\begin{tabular}{|l|l|}
\hline \multicolumn{1}{|l|}{ Report Design Screen Function Keys } \\
\hline F5 & Add Field \\
\hline FB & Select a field to be moved, copied or resized \\
\hline F7 & Move a field \\
\hline FB & Copy a field \\
\hline Shiff $+[$ F7 & Change the size of a field \\
\hline
\end{tabular}

\section{Creating Default Reports with Ouick Layouts}

As the graphic on the previous page illustrates, when the Report Design screen is initially accessed, you are presented with a "clean slate." Only the bands appear on the work surface. The goal in designing any report is to select and strategically place the appropriate fields you would like your report to use. If you are new to the dBASE IV Report Design screen and want to quickly and easily place all relevant fields in a default report template, use the Layout menu's Quick Layout option:

1. Press $A$ Alt $+\square$ to access the Report Design screen's Layout menu.

2. Highlight its Quick Layout option and press Enter $\square$ to select it.

3. You can choose one of the following Quick Layout templates:

- Column: The most commonly used layout option, the column layout presents your data in rows and columns and can include a report introduction, page header, footer and report summary.

- Form: Presents your report as a vertical list of the field names.

- Mail Merge: Each record is printed on a separate "page." Your page dimensions can be defined as "label" size to product mailing labels.

A default report will be created. 
A typical Column quick layout would look something like this...

You'll notice that the Page Header band will automatically display the page number and current date. Your associated database or query file's field names are used as the column headings in the Page Header band.

The Detail Band contains the actual field templates (represented by $x$ 's for text fields, 9 's for numeric fields and MM/DD/YY for date fields), that correspond to the fields in

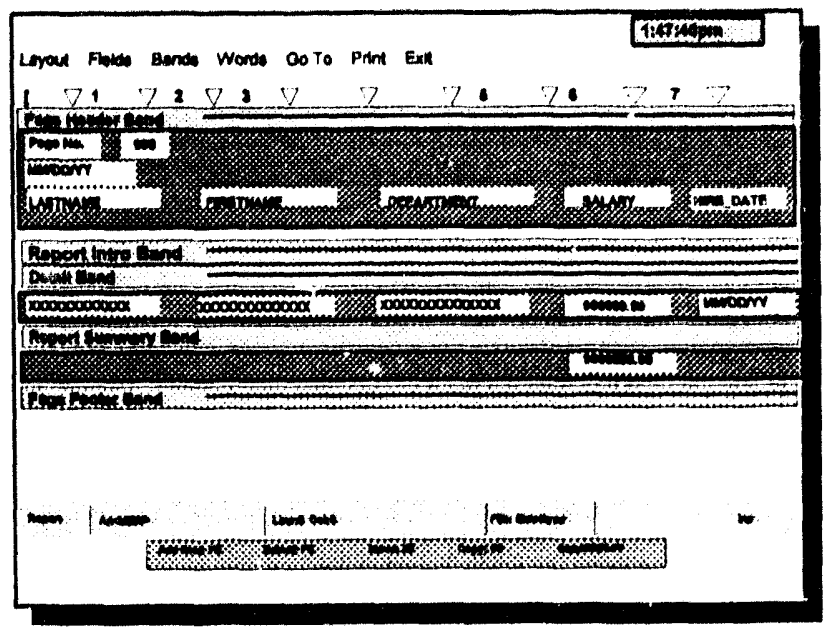
your report. They are placed directly beneath the appropriate field names as noted in the Page Header band.

The Summary Band contains a summary field for each numeric field in your associated database.

\section{Editing a Quick Layout Report}

While you may not ever actually use one of the default Quick Layout forms, you may find them helpful in getting you started as it is the quickest and easiest way to place all the associated fields in your report. Remember...you can delete any of the fields, move them to new locations, re-size them, change the information in your header or footer. It all depends on just how you want the final printed output to look! The following section will describe how you can design your own report, from scratch, or edit a previous Quick Layout report.

\section{Designing (and Refining) Your Own Report}

\section{Setting Margins with the Ruler}

When the Report Design screen first appears, the default left margin setting is established at 0 while the right margin is set at 240 . These settings assume that you are using compressed print on a wide (or landscape oriented) page. This is not typically the case. To reset the margins within a Quick Layout or in a custom report you are designing on your own:

1. Press Alt $+W$ to access the Words menu.

2. Highlight its Modify ruler option and press Enter - to select it. Your cursor will be automatically placed inside the ruler

3. Use your left and/or right arrow keys to position your cursor just where you want the new left and/or right margin(s) to appear

4. Type a right bracket (]) where you would like the right margin to be placed. A left bracket marker ( [ ) is used to define your left margin. 
Setting Margins with the Ruler, cont'd

5. Press Cirl + End to save this new margin setting.

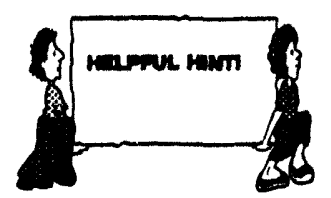

Typically, the right margin should be set somewhere between 65 and 75 if you are printing your report on an 8-1/2" $\times 11$ " page and a 10-12 character per inch font is being used.

\section{Remove Lines}

You may want to delete a complete line of information that was previously placed in a band (via the Quick Layout option, for example.) Simply place your cursor anywhere in the line you would like to delete and press $\mathrm{Cm}+\mathrm{Y}$. Or, you can press $\mathrm{Alt}+\mathrm{W}$ to access the Words menu and select its Remove line option.

\section{Add Blank Lines}

Perhaps you would like to add a more descriptive title in your page header. Or, you just want to insert a few blank lines to separate it more dramatically from the body of your report. Place your cursor at the end of any line you would like to add lines below or at the beginning of the line you would like to add blank lines above. Make sure you are in "insert" mode. (You'll know this if the word insert appears at the right side of your Status Line. If it's not there, press your Ins key to toggle it on.) Then press the Enter - key the number of times necessary to insert the required number of blank lines.

\section{Placing Text in Your Report}

Descriptive text can be placed within any band of your report. Just position your cursor anywhere in the shaded area beneath the required band name anc! type the required text.

\section{Deleting Blocks of Text from Your Report}

1. Move the cursor to the beginning of the text you would like to delete

2. Press the Select function key, FG, followed by the appropriate arrow keys to highlight the entire block of text you would like to delete.

3. Press Del to remove the highlighted text. 


\section{Adding Database Fields to the Report}

If you don't use one of the Quick Layout options to put the fields in your report, you can add them one at a time...

1. Position your cursor within the shaded area beneath the band you where the field is to be placed in the report.

2. Press $A \mathrm{Alt}+F$ to access the Fields menu and select its $A d d$ field option... or... Press F5, the "Add field" function key. A "Fields Definition" box listing available fields will appear. It will look something like this:

\begin{tabular}{|c|c|c|c|}
\hline EMPLOYEE & CALCULATED & PREDEFINED & SUMMARY \\
\hline LASTNAME & <create> & Date & Average \\
\hline FIRSTNAME & & Time & Count \\
\hline DEPARTMENT & & Recno & $\operatorname{Max}$ \\
\hline SALARY & & Pageno & $\operatorname{Min}$ \\
\hline \multirow[t]{3}{*}{ HIRE_DATE } & & & Sum \\
\hline & & & Std \\
\hline & & & Var \\
\hline
\end{tabular}

3. The first column in this "Fields Definition" box will contain the name of your report's associated database or query file followed by the fieldnames contained within it. (Information regarding the other three field columns - Calculated, Predefined and Summary - follows.) Highlight the field that you would like to insert and press Enter $\square$.

4. A "Field Format" box will appear. This box will present information about the database field you have selected (its name, type, length and number of decimal places, if any.) You will also be presented with options that will enable you to control just how the field is displayed in the report. You can press Ctr +End at this point to accept the default format setting...or... proceed to make any changes as required...

- Template: A template represents a string of formatting symbols, one for each position in a

field. The template symbol specified controls what will be displayed in a particular position in a field. For example, the template symbol 9 says, "Display only numeric data at this position. If you were to enter a comma (,) inside your template, the comma would actually appear at that exact position when the information within that field is actually displayed or printed. To define a template, highlight the Template option and press Enter - The braces surrounding the default template will disappear, allowing you to make any necessary changes. Press Ctrl + End when you are finished entering your template information. Press Ctri +End once more to exit the Field Format box.

$\Rightarrow$ SPECIAL NOTE: Commonly used template symbols and template examples are noted in Appendix $\mathbf{C}$.

- Picture functions: The display of your field can also be altered with the Picture function. Unlike the Template function, Picture functions apply to the entire field, not just a portion 


\section{Adding Database Fields to the Report, cont'd}

of it. To define a picture function, highlight the Picture functions option and press Enter - Depending upon the field type you are adding, you will see either a Character Picture function menu or a Numeric Picture function menu. Highlight the function(s) that you would like to change and press the Enter $\rightarrow$ key to turn them ON or OFF. Press Cirl + End when you are finished selecting your picture functions and CtrI + End once again to exit the Field Format box.

5. Repeat steps \#1- 4 until all required fields have been placed in your report.

\section{Adding Predefined Fields}

dBASE provides special predefined fields that will display the current date, time, page or record number. Predefined fields can be placed in any band but, with the exception of the record number field, they are most often placed in Page Header and/or Footer bands. Access any of these predefined fields exactly as you would a normal database field, following the directions noted above. $\triangle$ SPECIAL NOTE: Format boxes to change the template or picture function are not presented when adding predefined system fields to your report.

\section{Adding a Calculated Field}

You may find a need to create a report that contains a new field - one that is not already a part of the report's associated database or view query - that is a result of a calculation. To create a calculated field:

1. Position your cursor within the shaded area beneath the band you where the field is to be placed in the report.

2. Press Alt $+F$ to access the Fields menu and select its $A d d$ field option... or...

Press F5, the "Add field" function key. The "Fields Definition" box listing available fields will appear.

3. Highlight the <create> marker in the Calculated column and press Enter $\square$

4. A "Calculated Field Description/Format" box will appear:

- Name: Although this is an optional step, it is generally recommended that you give your calculated field a name. You'll then be able to use this same calculation in other areas of your report. In addition, once you have given a name to your calculated field, you can use it within expressions you may build for other calculated fields in your report.

- Description: Optionally enter a detailed description (up to 80 characters long) about what the purpose of the calculated field is.

- Expression: You must specify a valid dBASE IV expression hare. Press Enter then, use the Shift $+F 1$ keys to access your "Expression Builder" pick list to help guide you through the fieldnames, operators and dBASE IV functions to include in your expression 


\section{Adding a Calculated Field, cont'd}

- Template, Picture functions: These options will enable you to determine just how the calculated field is displayed in the report. See step \#4 in the instructions for Adding Database Fields to the Report, previously noted.

\section{Deleting Fields from the Report}

Just highlight th $\approx$ field template you want to delete and press your Del key. The entire field template will be removed.

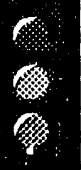

Be careful! Make sure that you have highlighted the appropriate field template to delete. Check your Status bar... it will tell you the name of any field template that the cursor is currently positioned at.

\section{Moving Fields and Text Within a Band}

If you have deleted field templates from your report, your line will not automatically "readjust" to accommodate for the free space left behind by the deleted item. To close this space, you may have to move other fields or text:

1. Position your cursor at the beginning of the field template or block of text you would like to move.

2. Press the Select function key, $F 6$, and use the appropriate arrow keys to highlight the entire field template or string of text. Press Enter when the entire item is highlighted.

3. Press the Move function key, F7. You'll notice a "ghost" box appear. Think of this as the "placeholder" for the item you are moving. It will help you determine just how and where it will fit in your report.

4. Move the "placeholder" box to its new location and press Enter $\rightarrow$ to "dump" the item at its destination.

$\checkmark$ SPECIAL NOTE: If you move a field or text so that its new position covers any part of its old position, a message will appear... "Delete covered text and fields $(Y / N)$ ?...Press $Y$ to have the item assume its new position.

\section{Moving Fields and Text Between Different Bands}

Text and/or fields being moved from one band to another can be relocated using the same steps as those for moving items within a band with one exception...before pressing the F7 Move key (see Step \#3, previously), use your arrow keys to position your cursor in the destination band. Then, proceed with Steps \#3 and 4 as noted previously 


\section{Creating Group Bands}

Group bands can be added to your report to organize your records by collecting them into groups. A group is defined by one of three qualities: record count, field value or dBASE IV expression.

Record count groups: Ask dBASE to group your records by a specifically defined number. For example, every 30 records.

Field value: Group your records by a value contained in your field. Using the sample Employee.dbf file, for example, you may start a new group each time the DEPARTMENT field changes.

dBASE IV expressions: Define an expression to group your records by. For example, you may want to group all those employees who make a salary that is below a specified amount.

IMPORTANT!!! In order for groups to work properly, you must index (or sort) the database in relation to the group value or expression you intend to use. (The file does not have to be indexed in any particular order if you are grouping by record number.) If the file is not indexed, your report will not be grouped according to your specifications. For example, if you were to create a report on the hypothetical Employee.dbf file and wanted to produce it so that employees are grouped by department, the DEPARTMENT index tag must be selected and currently active before the Reports utility is accessed. (Read more about creating and using index tags in PART IV, ORGANIZING YOUR DATA.)

Grouping information becomes important when you want to show subtotals within your report. You can also apply calculated functions within a group so that you could, for example, display the average salary of all the employees within each department.

\section{Group Band Components}

When a group band is added to your report, you are actually adding two bands: the Group Intro band and the Group Summary band.

Group Intro Band: The group intro band prints at the beginning each group. They normally contain the field template you are grouping the report by along with any other descriptive text you may want to display. This band usually contains information that remains constant along with data that changes. For example, if we were grouping our report by department, we may actually want to type the word, Department followed by an colon (:). Then the DEPARTMENT field would be added. The resulting information would look something like this in your Group Intro band. Department: XXXXXXXXXXXXXXXXXXXXX. The X's, once again, represent the DEPARTMENT field template and will notify the report recipient of the name of the department at the start of each new group. As a result, the beginning of the first group may read, 


\section{Group Band Components, cont'd}

Department: Accounting. The next group would be introduced in the report as Department: Budget Office. You see, the text Department: remains constant while the actual name of the department changes.

Group Summary Band: Calculate and display statistical information for your group in this band. The group summary band information is printed at the bottom of each group. Add a summary function in your group summary band just as you would any other database field (see the instructions on Adding Database Fields to the Report noted previously.) When you select one of the summary functions available (Average, Count, Sum, etc.), the function is performed only for each group. Using our report grouped by DEPARTMENT, for example, if we were to the place the COUNT summary field in the group summary band, the results would give us a count of all the employees in each department.

\section{Adding Group Bands}

1. Position your cursor to the border of the Report Intro band.

2. Press Alt $+B$ to access the Bands menu.

3. Highlight its Add a group band option and press Enter - to select it.

4. Highlight the Field value option in the menu that appears and press Enter $\square$.

5. Select the field you would like to group your data by.

A new Group Intro band will appear before the Detail band. Its corresponding Group

Summary band will appear beneath the Detail band.

6. Add any relevant text and/or fields to the two bands.

\section{Enhancing the Report Appearance}

The dBASE IV Report Design screen offers the necessary tools to change the way the printed words actually appear in your report. You can change the print style, align text and adu lines and boxes to enhance the appearance of your report. All of these settings can be saved to a ormat file that can be applied to other reports you create.

\section{Changing the Print Style}

You can change selected blocks of text or fields to be displayed in six different print styles: plain, bold, underline, italics, superscript and subscript. You can "block out" different sections of your report and apply various combinations of print style to give your reports a truly distinctive look

1. Position your cursor at the beginning of the block of text or field you would like to change.

2. Press the Select function key, F6.

3. Use your arrow keys to highlight the text you would like to change and press Enter - to complete the selection process. 


\section{Changing the Print Style, cont'd}

4. Press Alt $+W$ to access the Words menu.

5. Highlight its Style option and press Enter -1 to select it.

6. Move the cursor to the desired option and press Enter - to toggle it ON or OFF.

The new style that you have selected will not be evident in the Report Design screen. However, you'll notice that brightened characters indicate that the bold style has been turned on for selected items. Other print styles will be displayed in different colors that may vary depending upon your monitor type. The true style will be displayed in the printed output of your report.

\section{Aligning Text}

You can select certain text or fields and right align them, left align them or center them on your page.

1. Position your cursor at the beginning of the block of text or field you would like to change.

2. Press the Select function key, F6.

3. Use your arrow keys to highlight the text you would like to change and press Enter $\square$ to complete the selection process.

4. Press $A$ Alt $+W$ to access the Words menu.

5. Highlight its Position option and press Enter - to select it.

6. Highlight the position of your choice (Left, Right or Center) and press Enter $\square$ The selected item(s) will automatically shift to the specified location.

IMPORTANT!! Keep in mind that when items are selected to be re-positioned on your page, they are placed relative to the margins you have set. So, if you right-align text, for example, and it no longer appears on your page, odds are that your right margin is set to the right of your screen's view. Make sure you adjust your margins appropriately before positioning your text. See Setting Margins with Your Ruler as previously noted.

\section{Adding Boxes and Lines}

Lines and boxes, when properly placed, can be effectively used to enhance your report's appearance. Lines, for example, can be placed inside Group Summary bands to delineate group changes. Boxes can surround certain blocks of text so to focus attention on important information.

Lines...

1. Press $A$ Alt $+\square$ to access the Layout menu.

2. Highlight its Line option and press Enter - to select it.

3. Select either Single line or Double line or Specify a character of your choice to use as your line type.

4. Position the cursor where the line is to begin and press Enter - 


\section{Lines...cont'd}

5. Use your left and/or right arrow keys to create a horizontal line. Use the up/down arrow keys if you are creating a vertical line.

6. Press Enter 4 to end the line.

Boxes...

1. Press $A$ Alt $+\square$ to access the Layout menu.

2. Highlight its Box option and press Enter - to select it.

3. Select either Single line or Double line or Specify a character of your choice to use as your box type.

4. Position the cursor where the top left corner of the box is to appear and press Enter 4 .

5. Use the arrow keys to move the cursor to the destination of the lower right corner of the box. A temporary box is formed as you move the cursor.

6. Press Enter $\rightarrow$ to complete the box.

\section{Editing and Deleting Lines and Boxes}

1. Position the cursor at the beginning of the line or box to be edited

2. Press the Select function key, $\mathrm{F6}$ and move the cursor to highlight the entire line or box.

3. Press F7 to move the line or box...or...

Press F8 to copy the line or box...or...

Press Shift $+F 7$ to resize the line or box...or...

Press Del to remove the line or box.

\section{Saving a Report}

It is important to save the format of your report. As long as the report's format is saved, it can be retrieved and printed at a later date and used over and over. In addition, report formats can be retrieved and used as "templates" for other reports you want to create.

1. Press Alt $+L$ to access the Layout menu.

2. Highlight its Save Report option and press Enter - to select it.

3. When prompted, type a unique name for your report. (Remember...DOS file naming conventions apply: eight characters or less, no spaces, etc.)

You can also save your report by using the Report Design screen's Exit menu and selecting its Save changes and exit option. dBASE IV will automatically add a FRM extension to the report form's file name. 


\section{PRITINO THE RAPORT}

Reports can be printed from within the Report Design screen or from the Control Center screen. In either case, you will be presented with a Print menu to define your print options. To access this Print menu...

From the Control Center Screen: Highlight the name of the report form you would like to print in the Reports panel and press Enter - Select the Print report option.

From the Report Design Screen: Press Alt $+P$ to access the Print menu.

\section{The Print Menu}

The Print menu will, of course, start the print process for you when you select its Begin printing option. However, you may want to review the other options available in the Print menu before printing your report.

- You can select the Eject page now option to eject a page (or form feed one page) from your printer

- Select View report on screen to save some paper! Take a look at how your report will look on your screen before sending it to your printer.

\begin{tabular}{|l||}
\hline Begin printing \\
Eject page now \\
View report on screen \\
\hline Use print form \{\} \\
Save settings to print form \\
\hline - Destination \\
- Control of printer \\
- Output options \\
- Page dimensions \\
\hline
\end{tabular}

- Specify the Destination, Control of printer, Output options and Page dimensions through the print menu. These options were reviewed earlier in these notes. Please reference the QUICK REPORTS section for more details.

- Save settings to print form will allow you to save the printer settings that you have defined in a file. This print form file will contain all the printer specifications you made for the report...destination, control of printer, output options and page dimensions. When you select this option, dBASE IV automatically creates a name for the print form identical to the name of the report form but with a .PRF extension. You can change this default file name to any other unique name of your choice.

- After you have saved the print settings, you can re-use them on this, or any other report by selecting the Use print form option. When you highlight this option and press Enter $\square$ to select it, the curly braces will disappear, giving your the opportunity to type the name of the print form that stores the printer specifications you want to use. 
You can manage your files and issue many important DOS commands from within dBASE IV. To access dBASE IV's DOS Utilities...

1. At the Control Center screen, press Alt $+T$ to access the Tools menu.

2. Highlight its Dos utilities option and press Enter - to select it.

A file list will be displayed on your screen which notes the files in the currently selected default directory. You can use your up and down arrow keys to navigate through this list. If you would like to display the files in a different directory, place the cursor on the name of the directory and press Enter $\square$. You can also use the Zoom key, $F 9$, to display the current directory tree. This will enable you to quickly jump from one directory to another. Pressing F9 again will toggle you back to the file list screen.

The following table describes the options available through the DOS Utilities menu:

\section{DOS:}

- Perform DOS command: Use this option to issue DOS commands or manage your files without closing the dBASE IV program. Any valid DOS command can be entered at the prompt box that appears when you access this option.

- Go to DOS: This option will clear the dBASE IV screen and place you in a full-screen DOS window. dBASE IV is still opened, you have just temporarily "spawned" out to the DOS prompt. When you are ready to return to the dBASE IV Dos Utilities screen, type exit at the DOS prompt and press Enter $\square$.

- Set default drive:directory: As noted in the GETTING STARTED section, you can use this option to change the default directory that you want to read your dBASE data files from and save them to.

\section{FILES:}

- Change drive:directory: Similar to the DOS menu's Set default drive:directory option, this option allows you to change the directory currently set. Once a new drive and directory have been entered, its contents will be displayed in the file list on the DOS Utilities screen.

- Display only: Narrow the display of the files in the file list by entering a selection criteria. For example, if you only wanted to display a listing of your database files, you would enter *.dbf.

Appendix A, DOS Utilities, cont'd 


\section{SORT:}

Rearrange the listing of the files displayed by sorting them by... Name, Extension, Date \& Time or Size.

\section{MARK and OPERATIONS:}

Mark one or multiple files that you would like to perform a DOS operation on.

To mark one file, just move the cursor to the file you would like to mark and press Enter - . A . symbol will appear before the marked file's name. To mark multiple files (or unmark files) use the Mark menu options: Mark all; Unmark all or Reverse marks (this option will swap those tiles that are currently marked with any that are not.)

After you have marked the appropriate files, use the Operations menu to perform the required DOS command (Delete; Copy; Move; Rename) 
Appendix B

Basic dBASE Functions

\section{DATA TYPE CONVERSION FUNCTIONS:}

\begin{tabular}{|l|l|l||}
\hline Function & Description & Syntax \\
\hline STR( ) & $\begin{array}{l}\text { Converts a number to } \\
\text { a character string. }\end{array}$ & STR $(<$ numeric expression $>[,<$ length $>][,<$ decimal $>])$ \\
\hline VAL( ) & $\begin{array}{l}\text { Converts character } \\
\text { type data made up of } \\
\text { numerals into numeric } \\
\text { data. }\end{array}$ & VAL $(<$ character expression $>)$ \\
\hline DTOC( ) & $\begin{array}{l}\text { Converts a date } \\
\text { expression to a } \\
\text { character string in the } \\
\text { format MM/DD/YY }\end{array}$ & DTOC $(<$ date variable $>)$ \\
\hline DTOS( ) & $\begin{array}{l}\text { Converts a date } \\
\text { expression into a } \\
\text { character string in the } \\
\text { format YY/MM/DD }\end{array}$ & DTOS $(<$ date variable $>)$ \\
\hline CTOD( ) & $\begin{array}{l}\text { Converts a character } \\
\text { expression to a date } \\
\text { variable. An } \\
\text { alternative to this } \\
\text { function is using } \\
\text { braces around the date } \\
\text { to convert the } \\
\text { character text to date } \\
\text { format. }\end{array}$ & CTOD $(<$ character expression>) \\
\hline
\end{tabular}


Appendix B, Basic dBASE IV Functions, cont'd

DATE AND TIME FUNCTIONS:

\begin{tabular}{|l|l|}
\hline Function & Description \\
\hline DATE( ) & $\begin{array}{l}\text { Returns the current system date in the } \\
\text { form MM/DD/YY }\end{array}$ \\
\hline DAY( ) & $\begin{array}{l}\text { Returns the numeric value of the day of } \\
\text { the month. }\end{array}$ \\
\hline DOW( ) & $\begin{array}{l}\text { Returns a number corresponding to the } \\
\text { day of the week, with Sunday being } \\
\text { number } 1 .\end{array}$ \\
\hline MONTH( ) & $\begin{array}{l}\text { Returns a number corresponding to the } \\
\text { month with January being number } 1 .\end{array}$ \\
\hline TIME( ) & $\begin{array}{l}\text { Converts the system time into a } \\
\text { character string in HH:MM:SS format. }\end{array}$ \\
\hline YEAR( ) & Returns the year as a numeric value. \\
\hline
\end{tabular}


TEMPLATE SYMBOLS USED FOR NUMERIC FIELDS:

\begin{tabular}{|c|c|}
\hline Symbol & Function \\
\hline 9 & Presents only digits or a positive or negative sign. \\
\hline \multirow[t]{2}{*}{ \# } & Presents only digits, spaces and positive or negative signs. \\
\hline & Specifies the decimal point location in the field. \\
\hline , & $\begin{array}{l}\text { Displays a comma at this location if the number is large } \\
\text { enough to require it. }\end{array}$ \\
\hline * & Displays leading zeros as asterisks. \\
\hline$\$$ & Displays leading zeros as dollar signs. \\
\hline other & $\begin{array}{l}\text { Any other character entered in a template is inserted into } \\
\text { the display of the data. }\end{array}$ \\
\hline
\end{tabular}

Date Template Symbol Examples:

Data value

12345.67

1

12.34

5551212
Template

$99,999.99$

*999

$\$ 99,999.99$

999-9999
Report presentation

$12,345.67$

$* * 1$

$\$ \$ \$ 12.34$

$555-1212$ 
Appendix C, Template Symbols, cont'd

TEMPLATE SYMBOLS USED FOR CHARACTER FIELDS:

\begin{tabular}{|c|l|}
\hline Symbol & Function \\
\hline 9 & Displays digits and signs \\
\hline$\#$ & Displays aigits, signs, spaces and periods \\
\hline $\mathrm{A}$ & Displays alphabetic characters only \\
\hline $\mathrm{N}$ & Displays alphabetic characters, digits and the underscore \\
\hline $\mathrm{X}$ & Displays any character \\
\hline$!$ & Converts the database value to uppercase \\
\hline other & $\begin{array}{l}\text { Any other character entered in a template is into the } \\
\text { display of the data. }\end{array}$ \\
\hline
\end{tabular}

Character Template Symbol Examples:

Data value

cat

cat

555443333
Template

!!!

!AA

999-99-9999
Report presentation

CAT

Cat

555-44-3333 

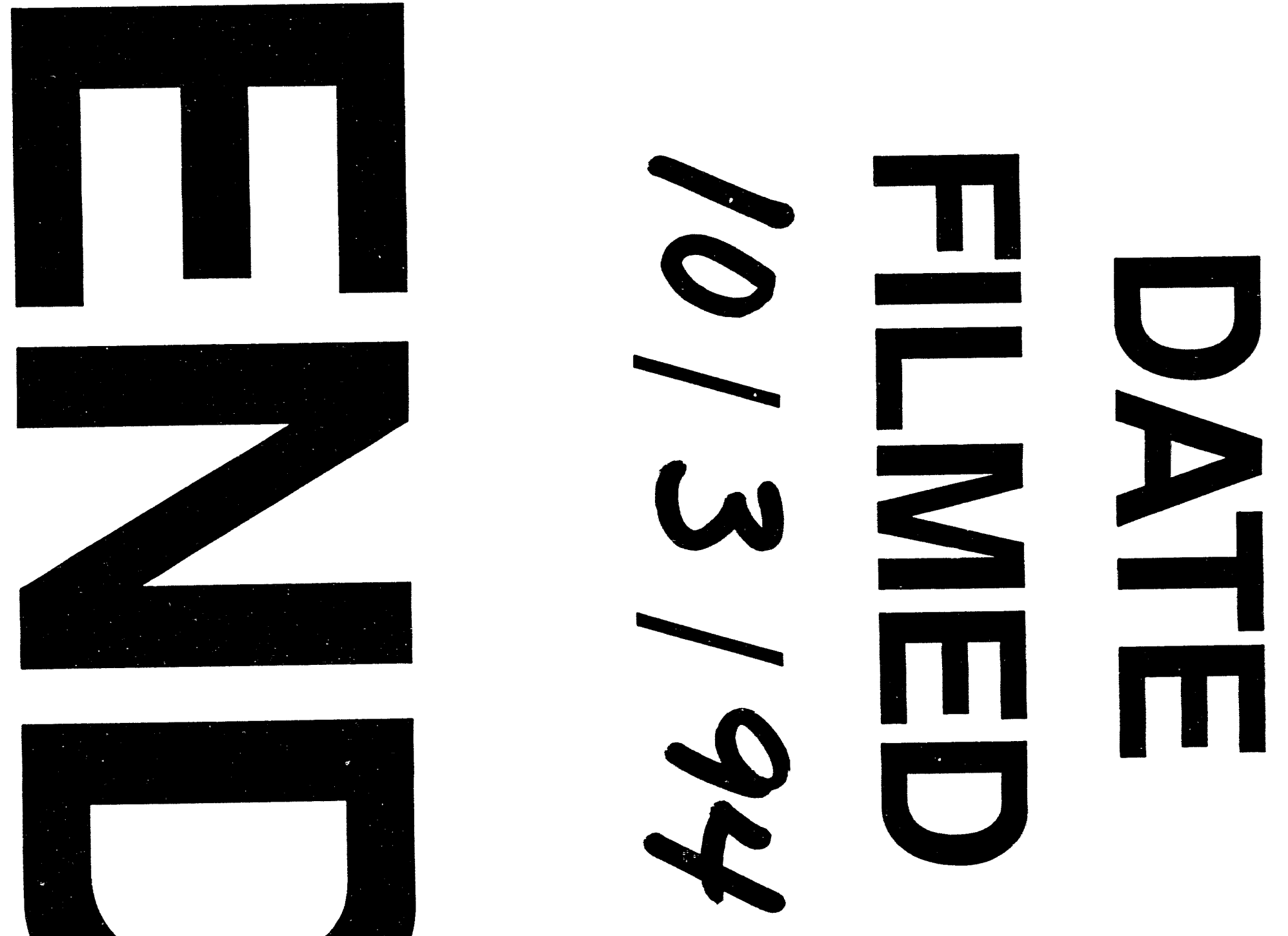


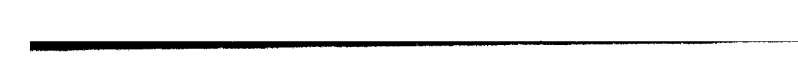

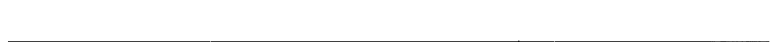

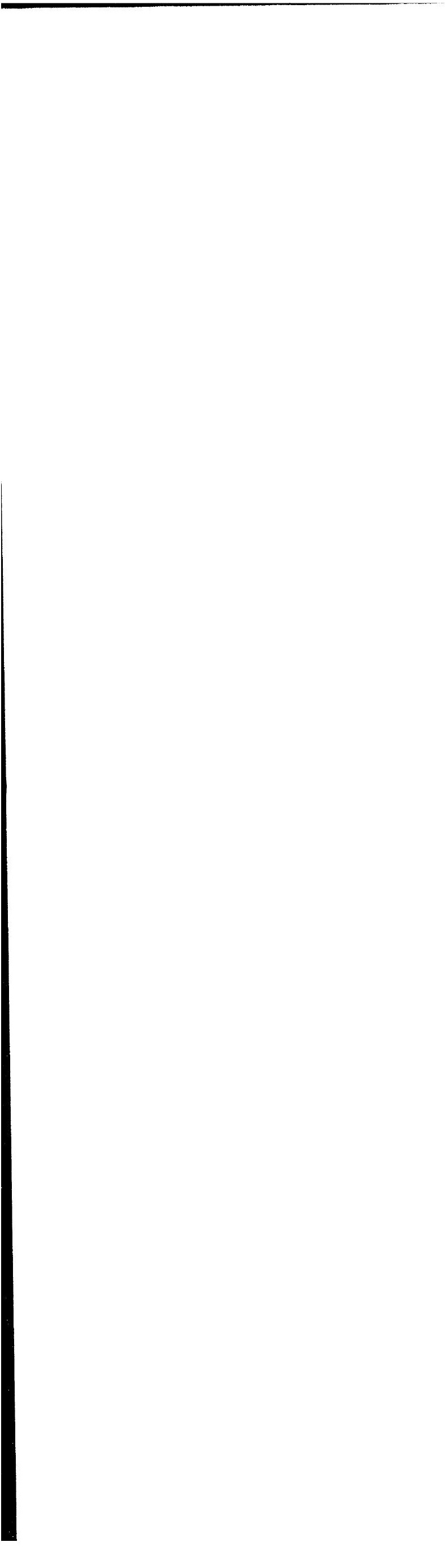
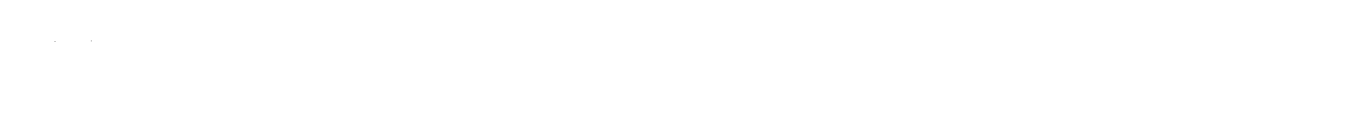
(1)
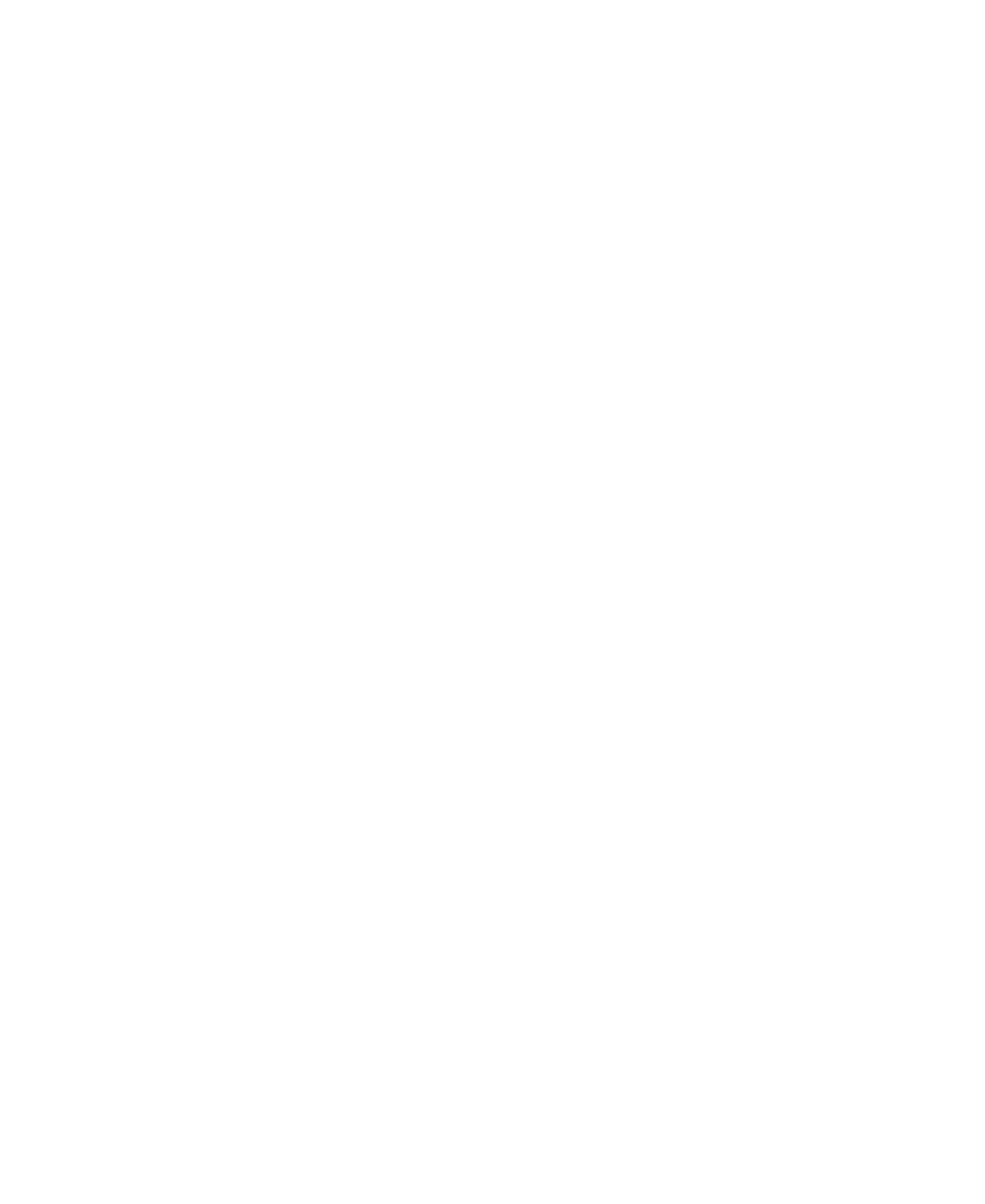